\title{
Evolution of fault permeability during episodic fluid circulation: Evidence for the effects of fluid-rock interactions from travertine studies (Utah-USA)
}

\author{
Emanuelle Frery ${ }^{\mathrm{a}, \mathrm{b}, \mathrm{f}, *}$, Jean-Pierre Gratier ${ }^{\mathrm{a}, \mathrm{g}}$, Nadine Ellouz-Zimmerman ${ }^{\mathrm{b}}$, Christelle Loiselet ${ }^{\mathrm{b}, \mathrm{h}}$, Jean Braun ${ }^{\mathrm{a}, \mathrm{g}}$, \\ Pierre Deschamps ${ }^{c}$, Dominique Blamart ${ }^{\mathrm{d}}$, Bruno Hamelin ${ }^{\mathrm{c}}$, Rudy Swennen ${ }^{\mathrm{e}}$ \\ a Université Grenoble Alpes, ISTerre Grenoble, France \\ b IFPEN, Rueil-Malmaison, France \\ ' CEREGE, UMR Aix-Marseille Université - CNRS - IRD - Collège de France, Technopole de l'Arbois, BP 80, 13545 Aix-en-Provence, France \\ ${ }^{\mathrm{d}}$ LSCE, Gif sur Yvette, France \\ e KU-Leuven, Leuven, Belgium \\ ${ }^{\mathrm{f}}$ CSIRO, Kensington, Australia \\ g CNRS, ISTerre, Grenoble, France \\ ${ }^{\text {h }}$ BRGM, Orleans, France
}

\section{A R T I C L E I N F O}

\section{Article history:}

Received 6 January 2015

Received in revised form 17 March 2015

Accepted 26 March 2015

Available online xxxx

\section{Keywords:}

Structural geology

Travertine calibration

Fault activity

$\mathrm{CO}_{2}$-enriched fluids

Fluid circulation and leakage

Vein sealing

\begin{abstract}
A B S T R A C T
Faults are known to be important pathways for fluid circulation within the crust. The transfer properties along faults can evolve over time and space. The Little Grand Wash and Salt Wash normal faults, located on the Colorado Plateau, are well known examples of natural $\mathrm{CO}_{2}$ leakage systems from depth to surface. Previous studies dated and established a chronology of $\mathrm{CO}_{2}$-enriched fluid source migration along the fault traces and linked the aragonite veins observed close to Crystal Geyser to $\mathrm{CO}_{2}$-pulses. However, multiple circulation events recorded along a given fault segment deserve to be studied in minute detail in order to unravel the chronology of these events, precipitation processes and associated mechanisms. A combination of structural geology, petrography, U/Th dating, oxygen and carbon isotope analysis were used to study the fault related $\mathrm{CO}_{2}$-enriched paleocirculations in order to build a conceptual model of $\mathrm{CO}_{2}$-circulation along the faults. This study resulted in the precise descriptions of the features attesting $\mathrm{CO}_{2}$-enriched fluid circulation by a characterization of their relationship and architecture at the outcrop scale. These features are witnesses of a large range of circulation/sealing mechanisms, as well as changes in fluid chemistry and thermodynamic state of the system, providing evidence for (i) the evolution of the fluid through a pathway from depth to the surface and (ii) different cycles of fault opening and sealing. Large circulation events linked with fault opening/sealing are observed and calibrated in nature with millennial circulation and sealing time-lapses. Numerical modelling indicates that such sealing timescale can be explained by the introduction of a fault sealing factor that allows modifying permeability with time and that is calibrated by the natural observations.
\end{abstract}

(c) 2015 Elsevier B.V. All rights reserved.

\section{Introduction}

Fluid advection (Cox and Etheridge, 1989), channelled along crustal faults, regularly occurs in the Earth's crust (Marques et al., 2010; McCaig, 1988). Faults represent main pathways for fluid flow from deep reservoirs up to the surface, but faults can also act locally as impermeable barriers (Person, 2007). Consequently, faults may successively act as open or closed pathways. Their opening can be triggered by earthquakes, fluid overpressures or localized dissolution (Gratier and Gueydan, 2007). Their closure can be linked to progressive sealing due to mechanical (Eichhubl et al., 2000; Hancock, 1999; Solum et al.,

\footnotetext{
* Corresponding author at: CSIRO, Kensington, Australia. Tel.: +61 487511885

E-mail address: emanuelle.frery@csiro.au (E. Frery).
}

2010), and chemical processes (Renard et al., 2009). Consequently, the relative fluid transfer properties change in space and time within natural faults, i.e. porosity and permeability variations may occur (Kopf et al., 2000). These are crucial controlling parameters in relation to earthquake chronology and frequency (Fitzenz and Miller, 2001; Gratier, 2011; Micklethwaite and Cox, 2004).

Exhumed examples of such systems are located in the Colorado Plateau, namely the Little Grand Wash (LGW) and Salt Wash (SW) normal faults. These sites provide a way of observing the natural $\mathrm{CO}_{2}$ Circulation along faults and the leakage at the surface that has taken place over thousands of years. The investigated area provides a unique opportunity to collect direct data to calibrate fault-related discharge. The leakage of $\mathrm{CO}_{2}$ along faults has been identified and documented in previous studies showing a spatio-temporal migration of $\mathrm{CO}_{2}$-enriched fluid 
leakage zones along the faults (Burnside et al., 2013; Dockrill, 2005; Dockrill and Shipton, 2010; Kampman et al., 2012; Shipton et al., 2004). This leakage has been evidenced to start at least $400 \mathrm{ka}$ ago and the U-Th dating of aragonite veins indicates that the recorded $\mathrm{CO}_{2}$ pulses can be related to glacial cycles (Kampman et al., 2014). However important questions remain to be addressed: i.e. (i) Can the structure and the processes of the circulation pathways from depth to the surface be unravelled by a close analysis of the different features attesting paleo-fluid flows observed in the fault zones? (ii) What are the fault opening and sealing mechanisms and their evolution with time?

The partially exhumed LGW and SW faults offer the possibility to examine the link between the fault activity and the fluid flow history recorded along a given fault segment. In order to unravel the precipitation conditions, this study focuses on a close study and classification of observations of paleo and modern circulation made along the faults, from structural field observations to thin-section petrographic analyses. In addition, the opening and sealing time-lapses of selected compact veins has been constrained by precise $\mathrm{U} / \mathrm{Th}$ dating and stable isotope analyses. Finally, the influence of the fault sealing on the duration and rate of fluid flow circulation is numerically tested. A post-seismic sealing process of the fault is incremented in a numerical model of Darcy flow in order to understand the reasons why and how the circulation decreases and stops along a fault, depending on the relative value of various parameters such as the fault structure and the fluid flow properties (Faulkner et al., 2010; Miller, 2013). Using an exponentially decreased evolution of the permeability with time, we finally discuss our results which explain the sealing time-lapses observed in nature and provide an evaluation of the fault sealing factor.

\section{Geological settings}

LGW and SW faults are located in Utah within the northern part of the Paradox Basin (Fig. 1A). This study area is located at the front of the extensive Sevier Fold-and-Thrust Belt that borders the western and northern part of the Colorado Plateau. The structure of the Paradox Basin results from a complex structural history well summarized by Peterson (1989), Hintze (1993), Barbeau (2003) and Trudgill (2011). The NW-SE Paradox Basin developed as a foreland basin with the Uncompaghre Uplift. High subsidence rates made the basin filled with thick Paleozoic sediments reflecting alternation of deep marine and very shallow water restricted depositional environments (Barbeau, 2003). Since Permo-Triassic times, these ductile evaporitic layers largely influenced the tectonic style in the Basin, by salt diapirs and development of large roll-overs (Hintze, 1993). From Cretaceous to Oligocene, the NE/SW Sevier and Laramide orogenies reactivate the fault system formed by the Permian the Basin elongation, such as the Moab fault, Lisbon Fault, Little Grand Wash and Salt Wash faults (Pevear et al., 1997; Solum et al., 2010). The Laramide thick deformation also resulted in basement inversions such as the San Raphael Swell and Monument uplift (Fig. 1.A). Finally, the current rising of the Colorado plateau and E/W Basin and Range tectonics keep the zone under an active extensional regional stress.

Ten Mile graben and Crystal Geyser areas (Fig. 1B, C) constitute the main $\mathrm{CO}_{2}$ leakage zones along the LGW and SW faults respectively. Modern and paleo-leakages of $\mathrm{CO}_{2}$-enriched water are documented by the occurrence of active and fossil travertines (Fig. 1B, C, D). In this article, we follow and extend the travertine designation adopted in the Dockrill thesis (2005). For that reason, the classification begins in Crystal Geyser area, labelling the active travertine T0 and the 4 ancient travertine mounds T1, T2, T3 and T4 (Fig. 1C, D, E), incrementing from the east to the west. In Ten Mile graben, two ancient travertine mounds are located close by the modern bubbling sources (Ten Mile Geyser and Ten Mile spring) and are called T5 and T6 (Fig. 1B, E). Toward the east, other ancient travertines have also been spotted along SW fault; we called T7 the major outcrop of this series (Fig. 1B).
Travertine is a term used to qualify carbonate precipitations under near ambient conditions in continental areas (Crossey et al., 2006; De Filippis et al., 2011, 2013b,c; Pentecost, 2005). In the study zone, modern travertines are currently formed by $\mathrm{CO}_{2}$ bubbling springs and geysers. The fossil travertines, where $\mathrm{CO}_{2}$ sourcing stopped some while ago, have been formed from less than 1 ka to 400 ka BP (Burnside, 2010). These endogenic travertines are characterized by a complex structure but overall two main features can be distinguished, i.e.: "surface travertines" and "travertine veins" (Altunel and Hancock, 1993; De Filippis and Billi, 2012; De Filippis et al., 2013a). The term "surface travertine" is used for the layered carbonate deposition that formed at the surface, whereas the term "travertine veins" corresponds to the travertines formed in fractures at shallow depth (Hancock et al., 1999) (Figs. $2 \& 3$ ). The travertine veins are mainly formed from aragonite and have a heavy $\delta{ }^{13} \mathrm{C}$ composition ranging from $+4.4 \%$ to $+7.2 \%$ 。 (Burnside, 2010; Dockrill and Shipton, 2010; Heath, 2004; Kampman et al., 2012) indicating a thermogenic origin based on Pentecost's definition (2005). The term "thermogenic" here relates to the deep underground $\mathrm{CO}_{2}$-enriched water supply rather than the current water temperature as usually referred to in many travertine studies (Bargar, 1978; Curewitz and Karson, 1997; De Filippis et al., 2012; Sella et al., 2014; Uysal et al., 2007, 2009; Vignaroli et al., 2014). For instance, in Crystal Geyser area the leaky bubbling water temperature is about $17{ }^{\circ} \mathrm{C}$. At depth, the $\mathrm{CO}_{2}$ is dissolved in the water and the exsolution takes place within the 100 uppermost meters below the surface (Assayag et al., 2009) and the $\mathrm{CO}_{2}$ arrives at the surface in two phases, namely dissolved in the water and as free gas. At present day, the gas sampled in the Geyser bubbles contains more that $98 \%$ of $\mathrm{CO}_{2}$, with a $\delta^{13} \mathrm{C}\left(\mathrm{CO}_{2}\right)$ ranging from -7.6 to $-5.7 \%$ o (Gilfillan et al., 2008, 2009; Jandel, 2008; Jandel et al., 2010) indicating an inorganic origin of the $\mathrm{CO}_{2}$, probably resulting from reactions within the crust or mantle. This $\delta^{13} \mathrm{C}$ range likely indicates an overlap between "crustal" and "mantle" $\mathrm{CO}_{2}$ (Wycherley et al., 1999). Stable oxygen and hydrogen isotope data demonstrated that about $90 \%$ of Crystal Geyser water comes from a shadow groundwater (Kampman et al., 2009). However, the chemical and isotopic analyses of the water of Green River area, and of the pore water from an oil field (Greater Aneth) located some $150 \mathrm{~km}$ to the SE of Green River, suggest a mix origin from the regional Jurassic Navajo aquifer and the Paradox Basin brine (Heath, 2004; Shipton et al., 2004).

\section{Methods and sampling}

This study integrates structural geology, petrography, oxygen and carbon stable isotope geochemistry and $\mathrm{U} / \mathrm{Th}$ dating in order to develop a conceptual model of the spatiotemporal variations of fluid flow along faults and to calibrate the $\mathrm{CO}_{2}$ leakage dynamics.

\subsection{Structural geology and petrography}

The first step of our study consisted in a structural investigation of modern and paleo-fluid flow architecture through the fault zones. This investigation is based on field work and petrographic analyses grouping observations from outcrop to thin-section scale. More than 300 samples were collected and analysed. In order to differentiate the distinct phases of carbonate precipitation, samples were stained using alizarine. Subsequently, to differentiate calcite from aragonite, the Feigl staining at room temperature was used on polished samples and thin sections (Kato et al., 2003). The solution was prepared according to the original recipe (Feigl and Leitmeier, 1933). Surface areas composed of aragonite immersed in this stain changed gradually from white to black over a 10-minute period.

\subsection{U/Th dating and stable isotopes}

An accurate chronology of the building of T1 travertine was established by absolute U-Th dating. Nine veins were collected along 

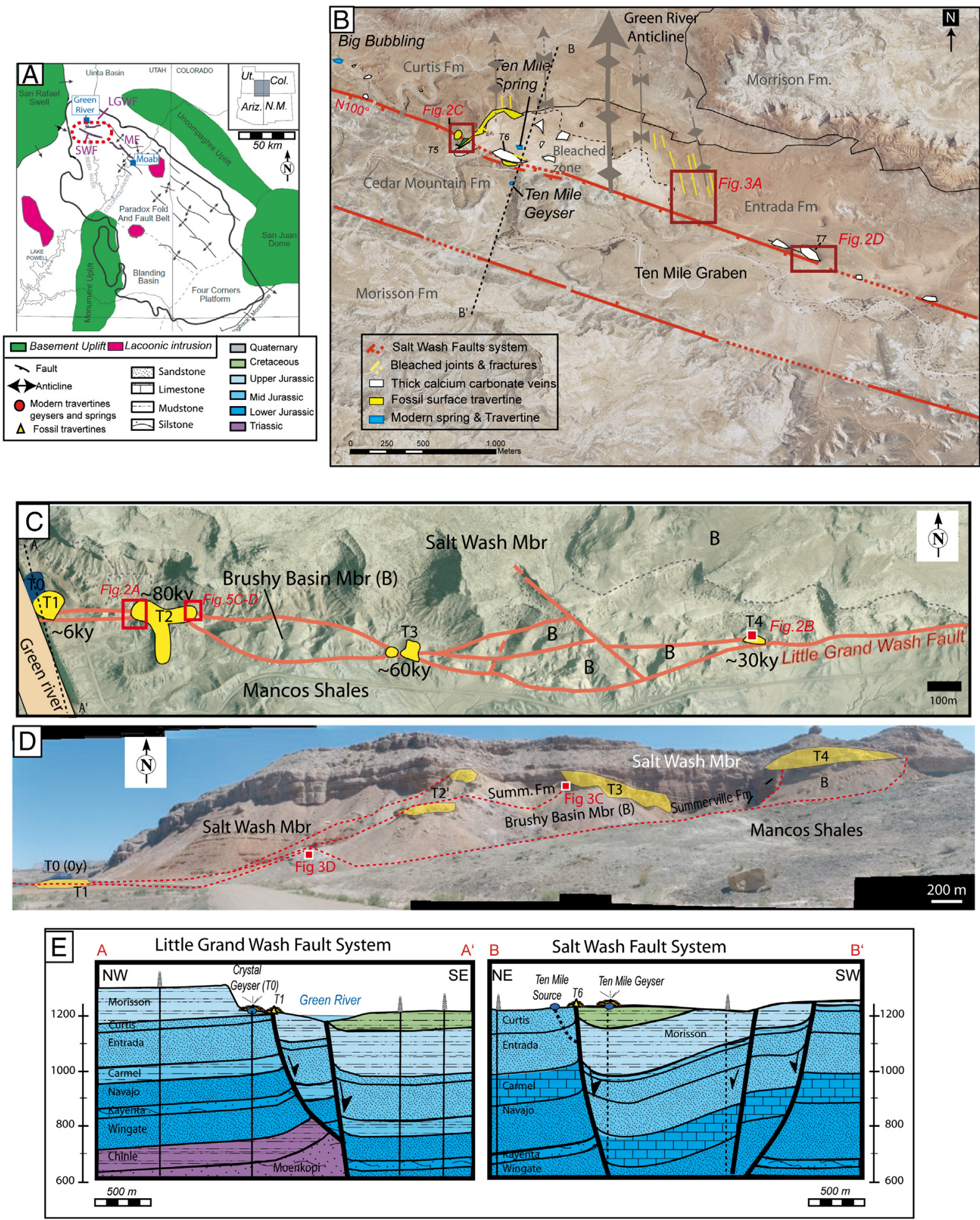

Fig. 1. Presentation of the studied area: (A) Location of the Little Grand Wash and Salt Wash faults within the Colorado Plateau (modified from Condon, 1997). (B) Aerial view of Salt Wash fault. (C) Aerial view of Little Grand Wash fault. (D) Profile view from the south of Little Grand Wash fault modified from Dockrill, 2005; Doelling, 1993). (E) Synthetic cross-sections outlining the main studied faults - based on well correlation (Utah Oil and Gas Well logs database, 2014) and field observations. Cross-section AA': wells from NW to SE: Marland oil company 1 projected $1150 \mathrm{~m}$ eastwards; Glen Ruby et al. \#1-X (Crystal Geyser origin); Amerada Petroleum Corp 2 projected $400 \mathrm{~m}$ eastwards; Green River Unit 2 projected $1450 \mathrm{~m}$ eastwards. Cross section BB', wells from NW to SE: Mt Fuel Skyline Geyser 1-25; Ten Mile Geyser abandoned well; Greentown St 31-362216 projected 1450 m eastward.

the 10 meter-thick outcrop of the T1 edifice and 14 samples were selected for U-Th analyses. Prior to chemical separation and purification following procedure described in details in Deschamps et al. (2004), all samples were cleaned and digested in nitric acid. U-Th analyses were performed at CEREGE (Aix en Provence) by thermal ionization mass spectrometry (TIMS) using a VG-Sector 54-30 mass spectrometer (Deschamps et al., 2012). Typical uncertainties on ${ }^{234} \mathrm{U} /{ }^{238} \mathrm{U}$ and ${ }^{230} \mathrm{Th} /{ }^{238} \mathrm{U}$ ratios are better than $1 \%$ and $2 \%(2 \sigma)$ respectively, leading 

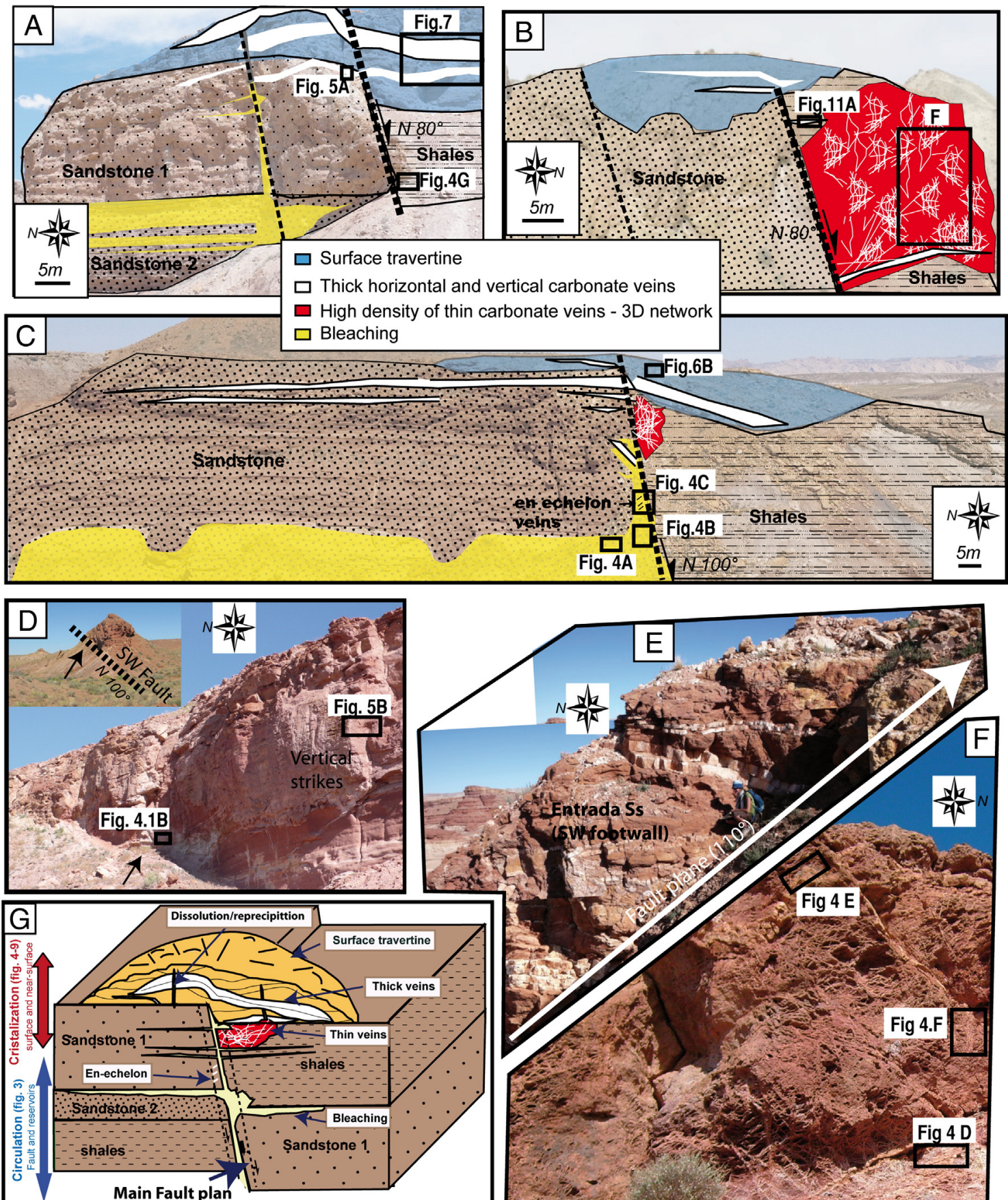

$\mathrm{N} 80^{\circ}$ for LGW fault to $\mathrm{N} 100^{\circ}-\mathrm{N} 110$ for SW fault

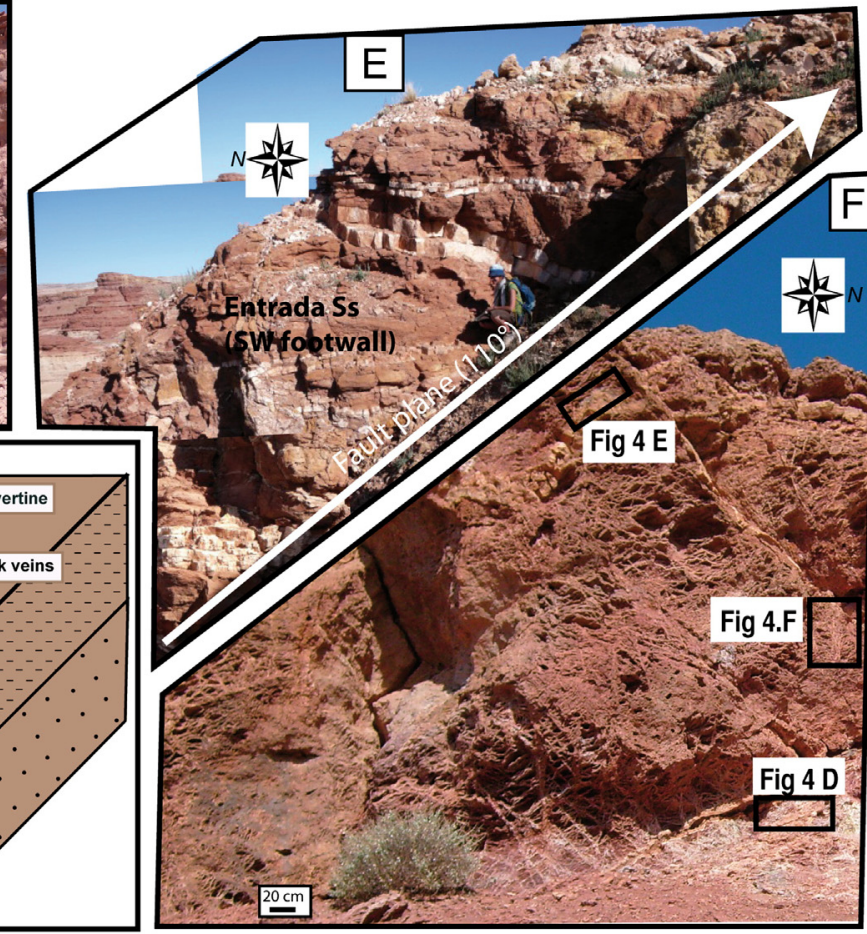

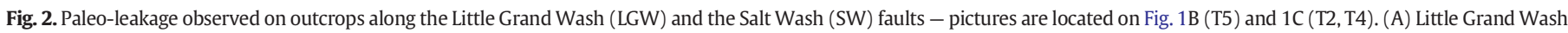

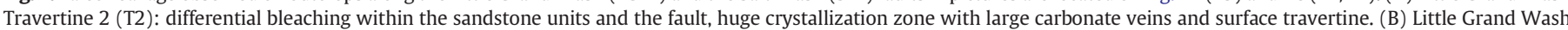

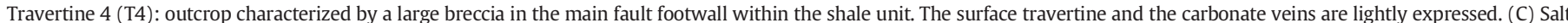

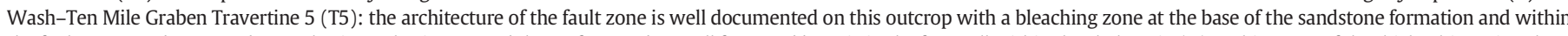

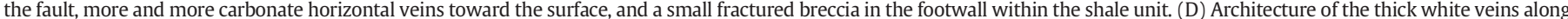

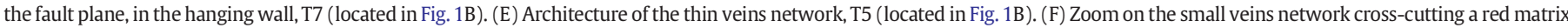
in the hanging wall of travertine $\mathrm{T} 4$ (located in Fig. $2 \mathrm{~B}$ as F). (G) Schematic diagram showing the $\mathrm{CO}_{2}$-enriched fluid flow features in the fault zones on natural outcrops.

to age error ranges between 9 and 27 years for the samples analysed in this study.

For stable isotope analysis, about 300 carbonate powders $(1 \mathrm{mg})$ were collected using a dental drill on polished sections of five dated veins and six undated veins. Analyses were performed with an optima micromass spectrometer (LSCE, Gif sur Yvette). The accuracy on the measurements is $\pm 0.04 \%$ and $\pm 0.06 \%$ respectively for oxygen and carbon isotopic compositions. The results are reported relative to V-PDB and are given in the classical delta notation (Coplen et al., 1983).

\subsection{Numerical modelling}

Results from the natural fault analysis have been discussed on the basis of a conceptual model of $\mathrm{CO}_{2}$-enriched fluid circulation along 

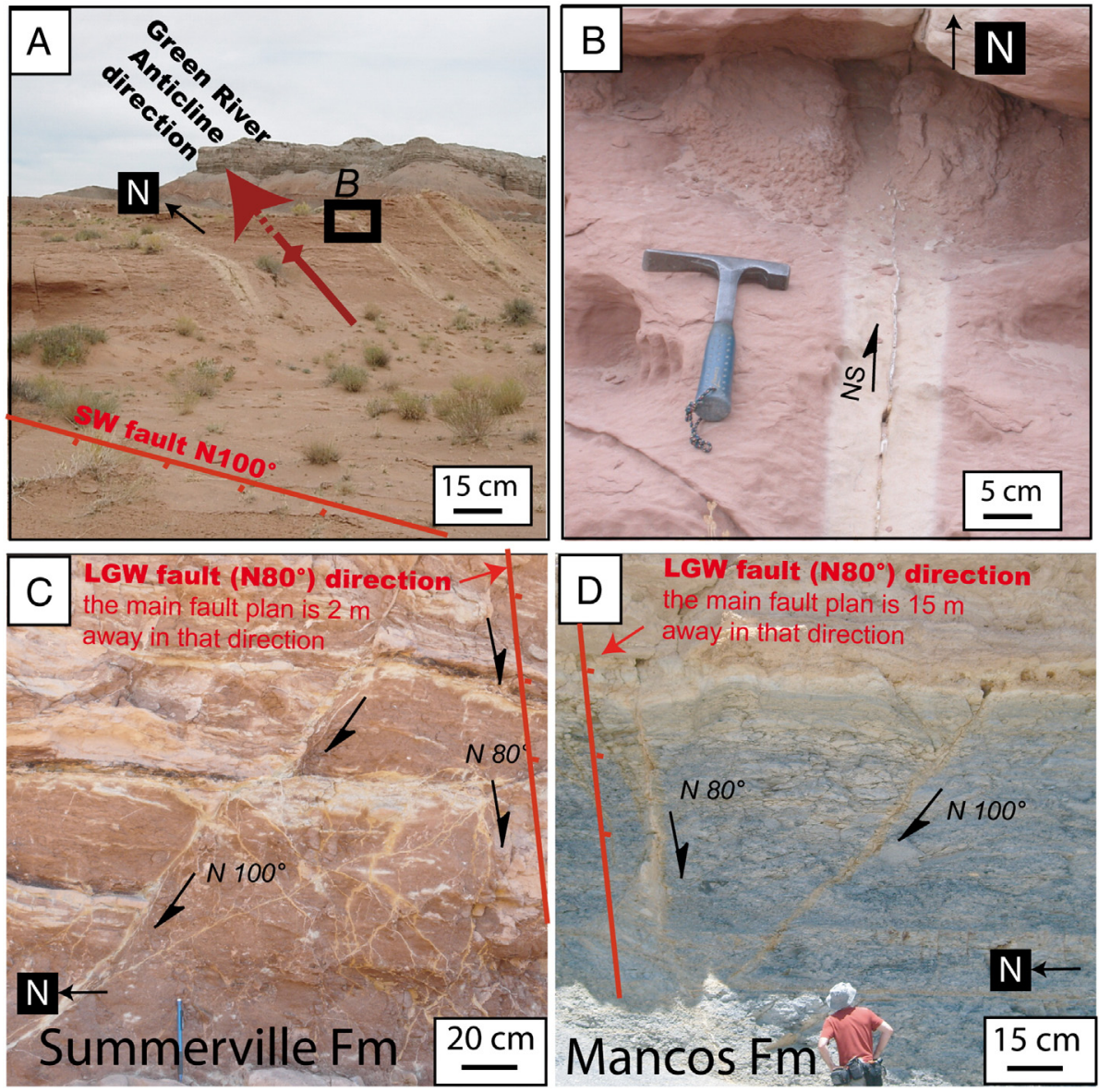

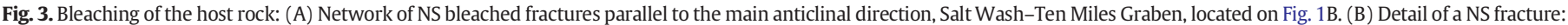

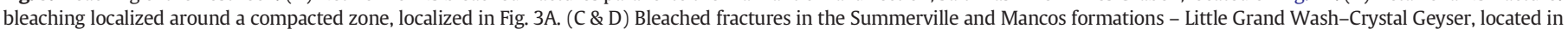
Fig. 1D.

faults. Following the discussion of this model and the associated fault permeability spatio-temporal evolution and opening/sealing mechanisms, a numerical analysis of the parameters influencing the fluid circulation time-lapses along a fault has been performed using the PERCOL code (Braun et al., 2003) in order (i) to test the validity of the conceptual model and (ii) to test the implication of the sealing timescales observed in nature on the fault geometry and permeability evolution. This 2D finite-element numerical model of fluid circulation along faults has been used to test the contribution of (i) Darcy flow, and (ii) a sealing factor acting in the area around the fault since drainage rate could be the main factor governing fluid flow variations along the fault. The model regards the fault as a conduit of very high permeability; it uses an adaptative mesh refinement algorithm around the fault, using Delaunay triangles and a logarithmic time stepping procedure which is designed to capture the response of the system to instantaneous changes in permeability or boundary conditions. See Braun et al. (2003) for further description of the model. The progressive sealing around the fault has been modelled using a time-dependent decreasing permeability law. Consequently, a new parameter namely the sealing factor accounting for the progressive sealing of the fault has been implemented in the Percol code. All numerical simulations are based on non-dimensional parameters.

\section{Natural results}

\subsection{Geological evidence of paleo-circulations with fluid-rock interactions}

Four representative outcrops, T2 and T4 along LGW fault, T5 and T7 along SW fault (Fig. 1.B, C, D), had been selected here to describe the near-surface fault architecture. The other travertine mounds have also been studied but they are not described in detail in this article as T3 and $\mathrm{T} 6$ characteristics are similar to $\mathrm{T} 4$ and $\mathrm{T} 5$ respectively. Note that $\mathrm{T} 1$ is studied in detail in part 4.2 .

Along Little Grand Wash fault, the travertine outcrops (Fig. 2A \& B) are localized on the fault relay, where all structural features of the fault segments merge toward a common point. Note that a high amount of carbonate precipitation is commonly observed in these specific zones along LGW fault. The travertine outcrops along the fault are indeed capped by a surface travertine or a thin layer of conglomerate, highly indurated by carbonate precipitations. Each of the selected outcrops illustrates a type of carbonate precipitation commonly observed in the field: for example, both thick carbonate veins and dissolution features are particularly well developed in travertine 2 (Fig. 2A) whereas travertine 4 (Fig. 2B) is characterized by a huge network of thin carbonate veins. The surface travertine, characterized by layered brown calcium carbonates, is particularly thick in the case of travertine 2 (Fig. 2A), reaching a thickness of $10 \mathrm{~m}$ in the central part of the outcrop. Considering the main fault $\left(\mathrm{N}^{\circ} 0^{\circ}\right)$, the surface travertine baseline is located at a lower level on the hanging wall rather than on the footwall of the fault. Note that this fault segment also separates two formations with completely different lithologies, namely shaly lithologies on the hanging wall, which are preferentially eroded and sandstones in the footwall. The surface travertine is crosscut by thick carbonate veins whereby a thicker vein also curves above the main fault in a normal direction. Finally, bleaching zones are localized along a fracture crossing the sandstone formation and also develop subparallel to the main fault segment. In the case of travertine 4 (Fig. 2B, F), the main fault segment $\left(\mathrm{N} 80^{\circ}\right)$ also separates two formations with different lithology with shale occurring in the hanging wall and sandstone in 
the footwall. However, the surface travertine is mainly located on the footwall side of the fault, without any spreading or thickening toward the hanging wall. The hanging wall is characterised by a huge network of thin carbonate veins occurring within a red shaly matrix (Fig. 2F). This red matrix colour contrasts with the surrounding rocks and only locally develops in the close proximity of the fault.

Outcrops along the northern segment of Salt Wash fault (Fig. 2C-E) are of major interest to study the bleaching phenomenon along both faults and fractures. The high cliff of T5 (Fig. 2C-E) allows a detailed study of the fault architecture, especially with regard to the evolution of the thick carbonate vein architecture. A large number of paleocirculation and leakage evidences are observable in this outcrop ranging from the development of a bleaching zone at the base to the formation of thick carbonate veins toward the outcrop top. All these events could attest circulation episodes of different fluids trough time or a synchronous circulation episode of the same fluid. The bleaching is only located in the basal level of the Entrada sandstones, within the footwall of the fault. In the SW fault system observed in Ten Mile, these sandstones are fluvial and the bleaching front gently follows the base of the main channels forming unbleached semi arc shapes (Fig. 2C). The regular sub-horizontal bleaching front is also affected by thin bleached joints and fractures. Along the main fault this front affects the sandstone higher up until the surface. Red matrix cross-cutted by a thin network of carbonate veins is also observable in the hanging wall. This system is nevertheless much thinner that in the case of T4 (Fig. 2B). Thick white veins are well developed toward the surface, especially in the footwall where they can be traced in the landscape along tens of meters. The surface travertine is well developed in the hanging wall, above the shaly formation. Toward the west of Salt Wash-Ten Mile graben the softer sediment of the hanging wall have been eroded, allowing a direct observation of the fault plane that is capped by a thick vertical carbonate vein within T7 (Fig. 2D).
Based on these field observations, the main features characterizing paleo-fluid circulation along the faults and fractures are summarized on a schematic diagram (Fig. 2.G). These features are, (I.) bleaching of the host rock, (ii.) carbonate precipitations in veins and surface travertines and (iii.) dissolution features located at the surface along the fault traces or directly within the outcropping fault gouges.

The following paragraphs and Figs. 3 to 9 aim at describing the structure of each of these features one by one, from the outcrop scale to the thin-section scale. In order to facilitate the understanding of the features location and orientation relatively to the main fault, each of the field photography are located on the relative outcrop and on the schematic diagram on Figs. 1 and 2.

\section{i. Bleaching of the host rock}

Bleaching is mainly encountered in red coloured sandstones, along eroded reservoirs, faults and fractures. Discoloured joints and fractures stripe the Entrada Sandstones in the SW fault zone, Ten Mile graben (Figs. 1B, and 2C, G). The outcrop zone, located at the top of a partially eroded NS anticline, allows detailed structural observations. A thick bleached zone is visible along the NE main fault segment, the discoloration decreases toward the north of the fault. Discoloration is also localized along NS joints, parallel to the main anticlinal direction (Figs. 1 and $3 \mathrm{~A}$ ). This discoloration progressively decreases toward the north of the graben. Gypsum mineralization had been founded at the centre of some of the bleached fractures. A detailed picture of the bleached fractures localized in the fault zone hanging wall and parallel to the LGW main segment direction $\mathrm{N} 80^{\circ}$ (Fig. $3 \mathrm{~B}$ ) shows that the bleaching is organized around central low permeability sandstone bordered by symmetrical bleached fronts, disappearing a few centimetres away from the central zone. In the Little Grand Wash-Crystal Geyser zone, the bleached area is also mainly localized in the lower sandstone levels of the outcrops
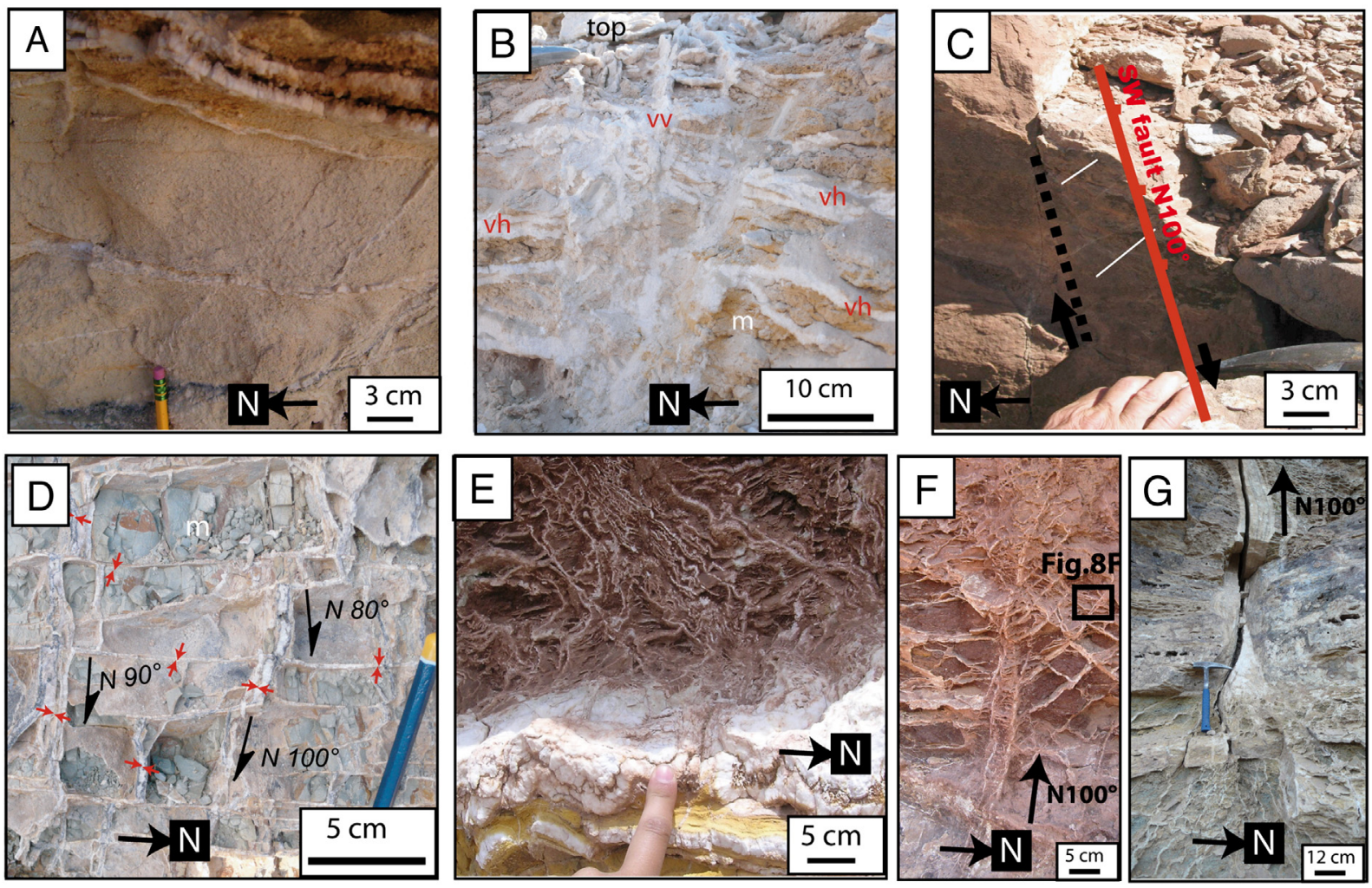

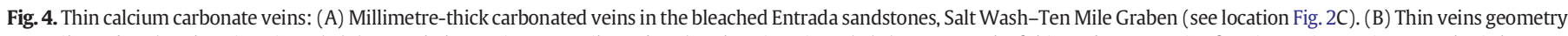

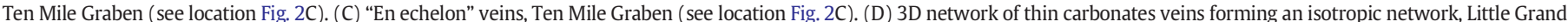

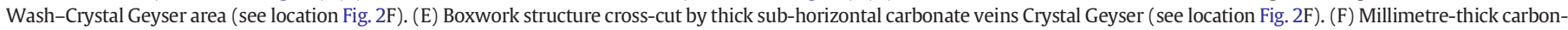

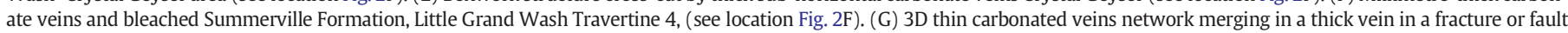
plane parallel to the fault direction within the Mancos shales, Little Grand Wash Travertine 2, (see location Fig. 2A). 

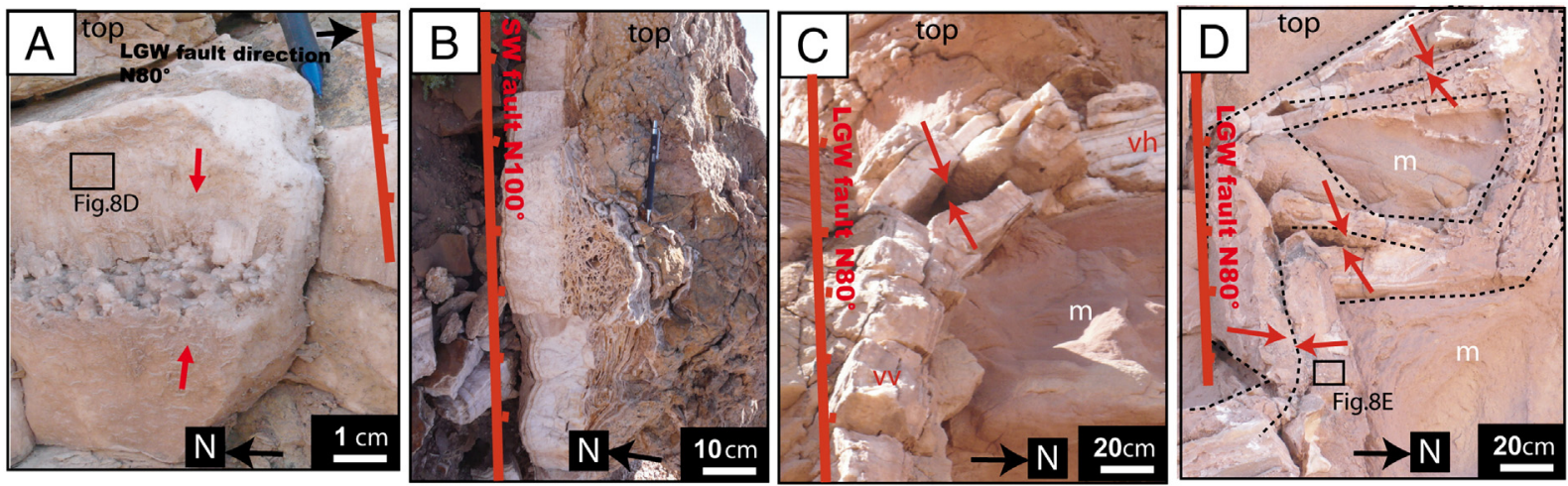

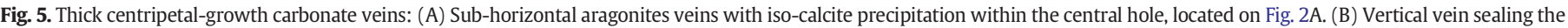

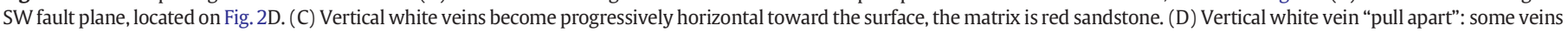
may temporary change of dipping, as a local effect of weakness of the wall-rock rocks or of micro-fractures (C \&D are located on the eastern side of T2, located on Fig. 1C).

that are caped by thick carbonate veins and surface travertine (Fig. 2A). Unlike the Ten Mile graben case, where the bleaching is not extensive and homogenous, here it is concentrated and aligned along fractures and lithological discontinuities (Fig. 3C). In the case of T2, the bleaching is localized around a sub-vertical fracture (Fig. 2A) crossing the sandstone matrix in the footwall of the main fault. Thick white veins crosscut the fracture. The bleaching affects the layered sandstone reservoirs around the fracture with a decreasing gradation from the base to the top of the outcrop. Thin bleached veins are also observed within the Mancos shales, within the damaged hanging wall of the fault (Fig. 3D). All these successive episodes of bleaching attest of circulation episodes of different fluids trough time.
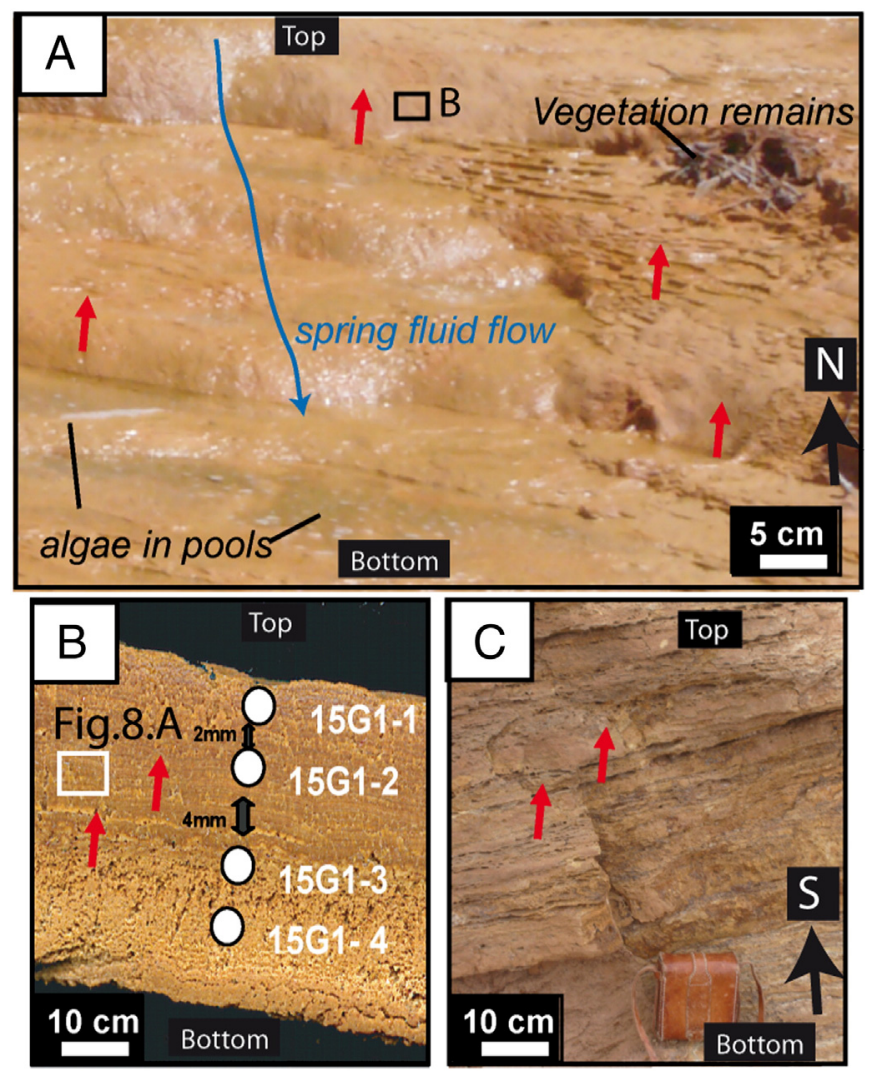

Fig. 6. Modern and ancient surface travertine: (A) Modern surface travertine with spring water flow, mud, algae and vegetation remains, Crystal Geyser (located on Fig. 1C). (B) Vertical profile of surface travertine growth (Located in Fig. 6A): oxygen and carbon stable isotopes have been analysed on 4 samples along this profile (15G1 serie). (C) Fossil surface travertine, Salt Wash-Ten Miles Travertine 5 (Located in Fig. 2C). ii. Calcium carbonate precipitations

- Thin veins

Two types of thin veins are distinguished: (a) Isolated millimetrethick calcium carbonate veins and (b) 3D dense network of veins leading to boxwork structure (Fig. 2G).

(a) Isolated millimetre-thick calcium carbonate veins (Fig. 4A-C) are observable in the basal part of the outcrops, within both sides of the fault, cross-cutting bleached and unbleached host rock. Main characteristic is the existence of a network of white thin veins with random geometry located just below thicker localized veins (Fig. 4A). The veins position can rapidly evolve from vertical to horizontal and some vertical veins also cross-cut horizontal veins (Fig. 4B). Few cemented thin "en echelon" veins have been observed in the Entrada sandstones, more specifically in the footwall of the fault in Ten Mile area. This geometry is in line with a normal fault movement (Fig. 4C).

(b) The density of the veins increases toward the centre of the fault zone where a 3D network of thin carbonate veins is observable (Fig. 4D-G). For instance, a huge (more than $10 \mathrm{~m}$ thick) boxwork structure is present in the hanging wall of LGW fault, below travertine T4 (Figs. 2B \& F and 4D-F). The shaly matrix is cross-cut by an isotropic boxwork of thin plugged veins, building a puzzle pattern (Fig. 4D). This structure is cross-cut by thick subhorizontal carbonate veins (Fig. 4E). In addition, at the base of the boxwork structure, localized thicker veins with a $\mathrm{N} 100^{\circ}$ orientation are present (Fig. 4F). At the base of the LGW T2 outcrop, a thin network of veins is observable as well. This vein system is located in the hanging wall of the fault, within the Mancos grey shaly unit (Fig. 4G) with a preferential direction of the veins along the fault plain. Toward the surface, this thin vein network eventually merges in a thick $(20 \mathrm{~cm})$ vein orientated in the fault plain direction. These networks of thin veins are often observable at the base of the thin carbonate vein edifices, mainly affecting shaly intervals. The vein networks can be isotropic like in the case of the LGW fault outcropT4 or preferential aligned in the fault plain direction, like observed in the case of LGW fault outcrop T2.

\section{- Thick veins}

Thick carbonate veins (up to $1 \mathrm{~m}$ thick) are observed in vertical direction within the fault plain and in horizontal position in the upper part of some of the outcrops (Figs. 2G, 5). The study of SW fault zone architecture (Fig. 2E) revealed that these thick veins are observable in the 

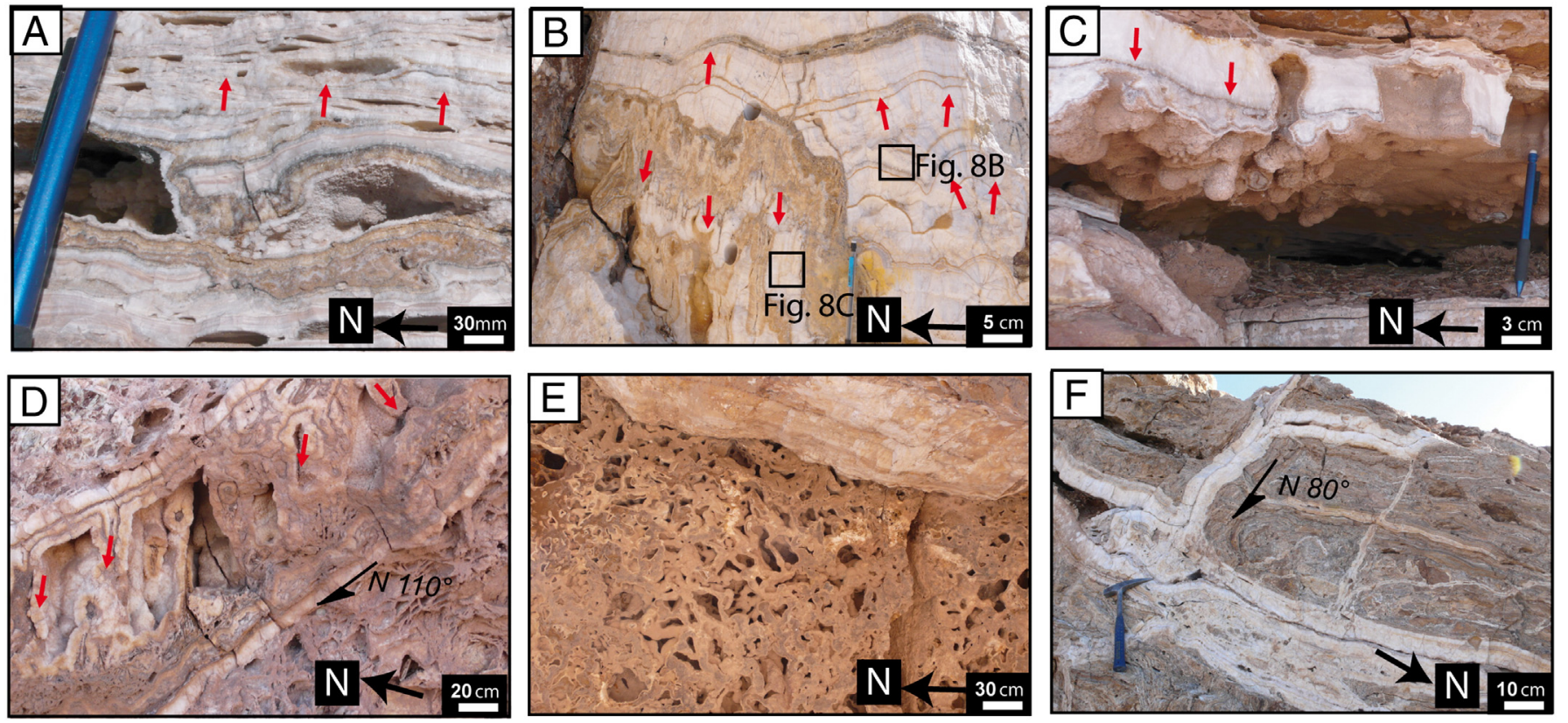

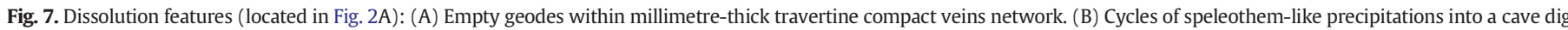

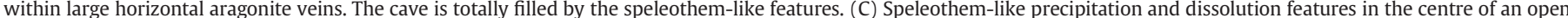

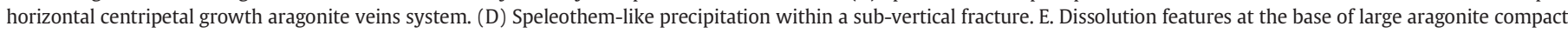
veins. (F) Precipitation and dissolution features in horizontal and vertical fractures.

sandstone host rock (footwall) from at least $10 \mathrm{~m}$ below the surface travertine topping the system, with an increase in vein thickness and density toward the top of the outcrops. The deepest veins observable are $15 \mathrm{~cm}$ thick whereas the veins at the top of the outcrop are about $1 \mathrm{~m}$ thick. Note that the vein thickness decreases rapidly away laterally from the fault zone and disappears within a few meters. Only the thickest veins observed at the top of the outcrop can be followed laterally over tens of meters (Fig. 2C). These veins merge and are clearly localized in one level within the sandstones. The hanging wall of the fault is composed of shaly Cedar Mountain lithology. Note that no thick veins crosscut this matrix. A surface travertine caps the shaly strata and thick veins cross-cut this carbonate structure. No vertical carbonate veins have been noticed along the fault plane in this outcrop case.

The thick vertical or horizontal veins often display centripetal growth features (Fig. 5A), however the thickest horizontal ones show a continuous top-to-bottom growth (see U/Th dating below). Such
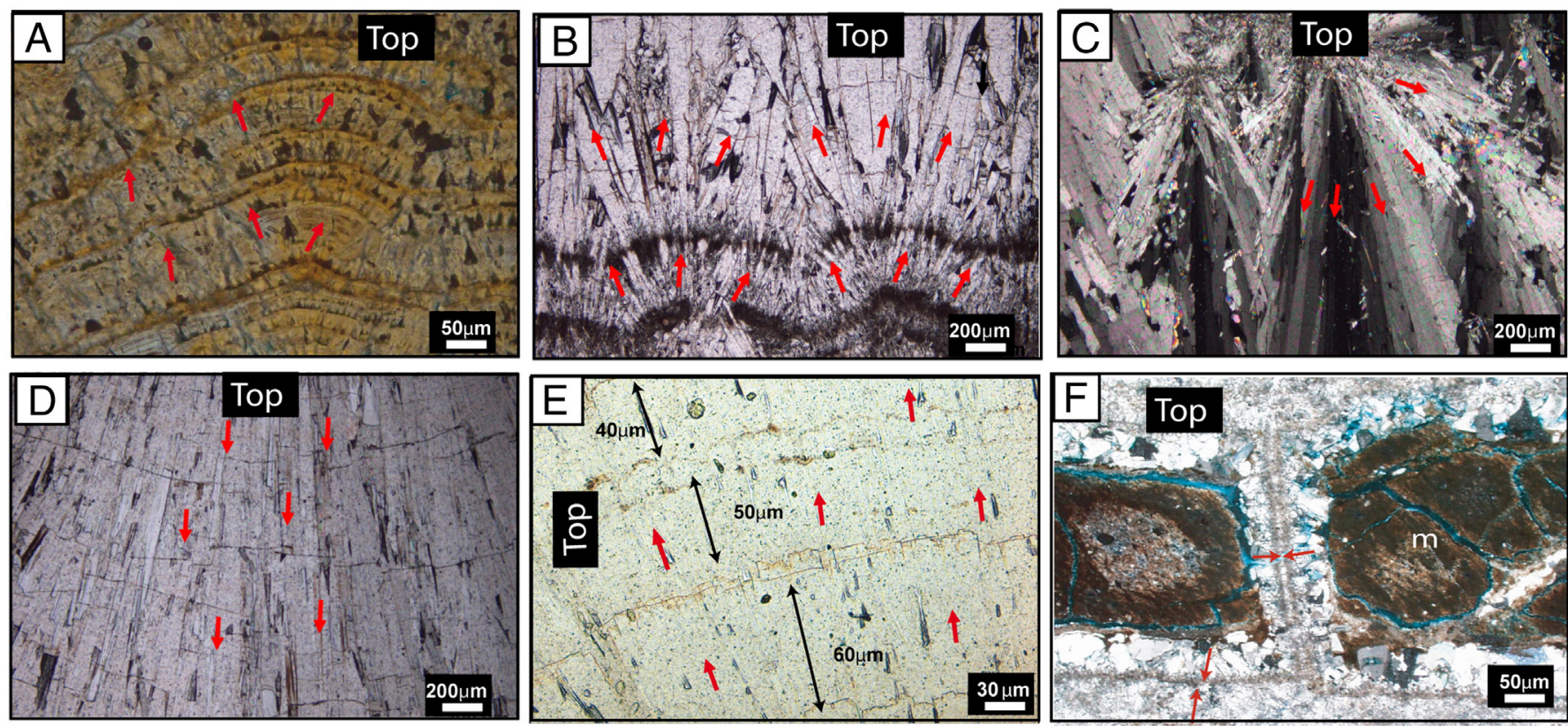

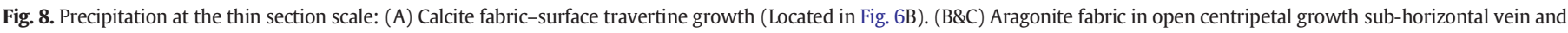

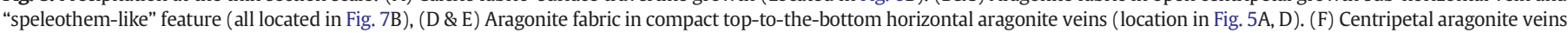
and clasts in a boxwork feature: noticeable demarcation between the silty matrix and the veins (located in Fig. 4F). 


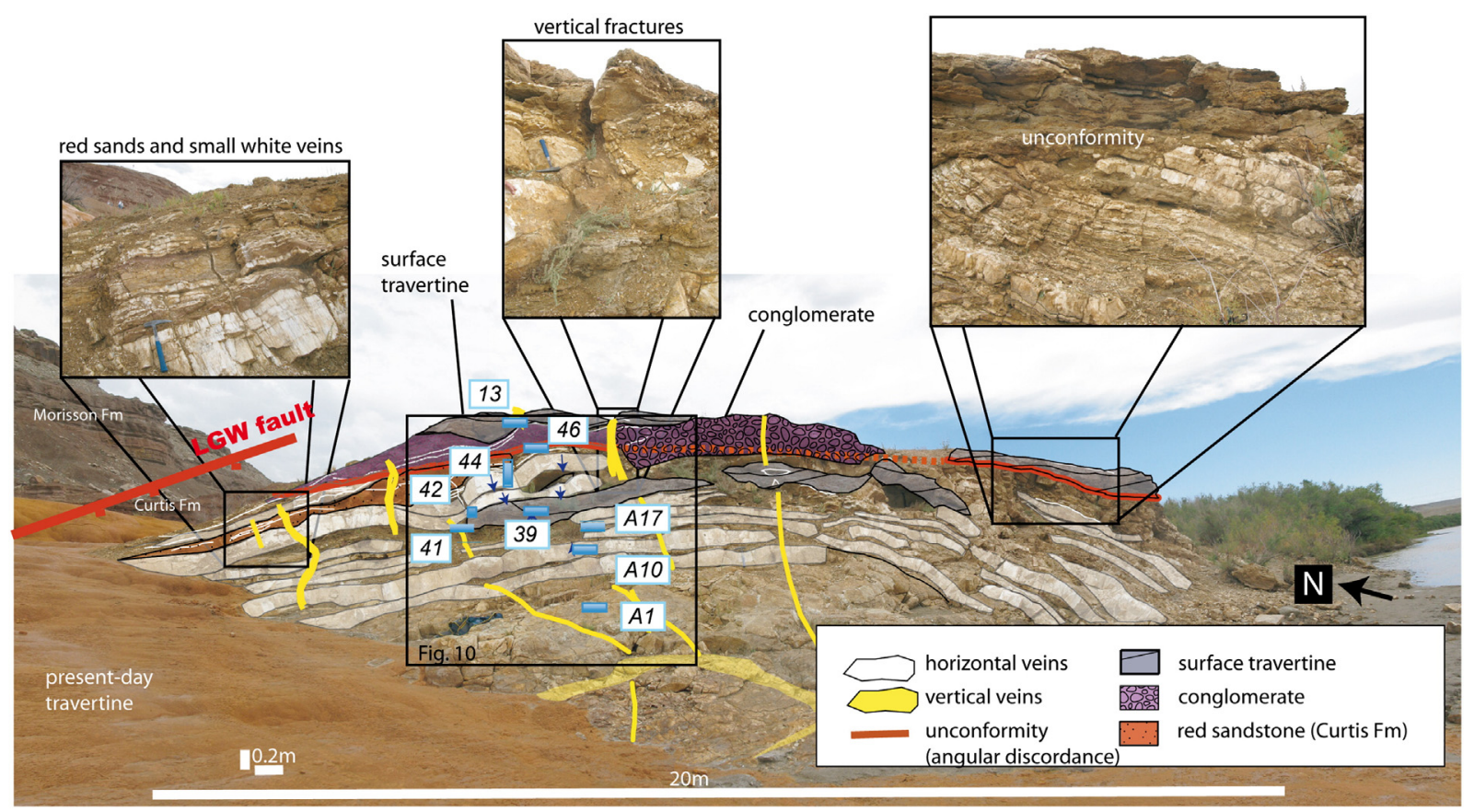

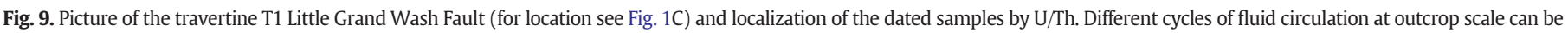

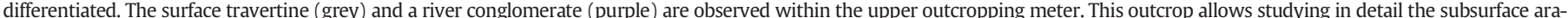

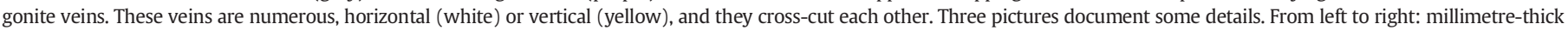

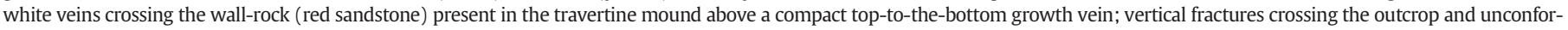
mity (angular discordance) at the top of the mound. (For interpretation of the references to colour in this figure legend, the reader is referred to the web version of this article.)

dense and compact horizontal veins are located at the top of the outcrop and cross-cut the surface travertine features. They are located in the fault vicinity and have been observed on a large number of outcrops. The LGW fault outcrop T2, is the more revealing example: the thick veins cross-cut the surface feature over several meters. In addition, the horizontal thick veins can also be cross-cutted by vertical veins.

Vertical veins are observable at the centre of some of the faults segments. One of the best examples is observable on the outcrops T7 localized toward the west of Ten Mile graben along the SW fault (Figs. 2D and 5.B). Vertical veins are present along the outcrop, exactly at the contact between the red sandstones of the footwall and the shales of the hanging wall. The shales have been preferentially eroded and vertical strikes affect the carbonate envelope of the veins located in the fault plane (Fig. 2D). Vein orientation may change progressively from a vertical to a horizontal direction after which it remains in this position till close to the surface (Fig. 5C), this phenomenon is observable along thick centripetal-growing veins, with a progressive curvature of the veins. The vein orientation can also vary locally around a piece of the hostrock (Fig. 5D). The contact between the vertical carbonate veins and the wall rock is sharp, supporting fracture mode 1 (structural mode). At outcrop scale, a clear dividing line between the matrix and the vertical white veins (Figs. 2E \& 5C-D) may indicate a rapid opening mechanism linked with fracturing events rather than free-face dissolution. Finally, when considering more than hundred of veins in the various travertine mounds it can be shown that carbonated vein size frequency decreases exponentially with vein width (Frery, 2012). However, in terms of precipitated volume, the largest veins represent most of the precipitated carbonates.

Briefly speaking there are two types of thick veins. The centripetalgrowing veins can evolve from vertical to near horizontal dip. They show the progressive sealing of open paths. Change of fluid composition evidenced by the various colours of the carbonates attested of the multiple fluid circulation episodes that progressively sealed such circulation paths. The development of the horizontal top-to-the-bottom growth compact veins is described in more details in the part dealing with the
$\mathrm{U} /$ Th dating. Such thick veins attest of fluid circulation along the fault that can be dated.

\section{- Surface travertine}

Ancient "surface travertine" systems cap the outcrops T1 to T7 along the LGW and SW faults (Fig. 2A, B, C, G). The classification of the "ancient surface travertine system" has been completed by analogy with the active Crystal Geyser system (Fig. 6A). The carbonate layers are clearly formed at the surface by the deposition of successive layers, and are lying above and plugging an alluvial conglomerate and some reworked clasts from the surrounding rocks (Fig. 6B and C). Consequently, the observed sub-horizontal laminations records successive episodes of fluid circulation. However, the mixing of carbonate precipitation and sediment and the partial erosion of such deposition renders the surface travertine difficult to analyse and interpret in term of successive episodes of circulation.

\section{iii. Dissolution}

Dissolution and reprecipitation features highly affect the carbonate system (Fig. 2G). For example vuggy porosity is very common in the ancient "surface travertine" systems. This porosity can be primary or due to secondary dissolution events. Cavities, from meter to centimetre sized, are present within the carbonate system (Fig. 5A). The best example is LGW travertine T2: a huge cavern has been created by dissolution in the central part of the outcrop (Fig. 7C). Close by, a smaller dissolution cavity is totally filled with speleothem-features (Fig. 7B). This mineralization however does not necessary fill all the open space. For instance, some cavities are only partially plugged by speleothem-like features (Fig. 7A-D). Thick compact veins observed at the top of the system in the SW T5 and LGW T2 outcrops, are compact and homogenous along a vertical profile. However on other horizontal faces the veins display a network of centimetre scale dip holes (Fig. 7E). 
Precipitation/dissolution/re-precipitation patterns (Fig. 7F) evidence the successive episodes of fluid transfer with episodic evolution of the fluid saturation.

\subsection{Structural and geochemical characteristics of the carbonate precipitations and fluid nature}

- Mineralization geometry

Thin section analyses revealed two main kinds of textures within the precipitates, namely fan shaped and linear textures. The active presentday surface travertine mineralization consists of laminated fans of calcium carbonate (Fig. 8A). Thin-section analysis within open or partially filled veins and cavities also reveal fan-shaped precipitations (Fig. 8B, C) made of primary aragonite. Colour variations (laminations) exist in these veins (Fig. 8B). The length/width ratio of the fans ranges between 0.5 and 2.5. Thin-sections within the compact top-to-thebottom growth veins (Fig. 8D, E) also reveal primary aragonite baguettes (that locally have been transformed into calcite). The difference between this texture and the centripetal growth vein relates to the fan angle. In the top-to-the-bottom growth veins the crystals are mainly arranged parallel to each other: parallel thin baguettes. Some thin black linear segments are observable perpendicular to the crystal growth direction. The increments measured between these lines vary around $40 \mu \mathrm{m}$ in length (Fig. $8 \mathrm{E}$ ).

Petrography of the isotropic boxwork structures (Fig. 8F) revealed the presence of millimetric-sized veins filled with centripetral-growth aragonite crystals. The symmetrical axis is in the centre of the veins.

- U/Th analyses and oxygen and carbon stable isotopes analyses

Here are analysed the thick centripetal-growing and top-to-bottom growing horizontal veins. These veins are mainly composed of aragonite fabric and are compact, that is to say that the mineral increments are linear, perpendicular to the vein growing direction (Fig. 8E) and that the vein sealing is not likely to be linked with a dissolution event followed by a free fluid circulation in cave environment. Travertine T1, located along LGW fault presents a large amount of these veins and thus represents the best study case (Figs. 1C \& 9). This outcrop is $20 \mathrm{~m}$ long and $5 \mathrm{~m}$ thick. A "surface travertine" and a conglomeratic river deposit, less than $1 \mathrm{~m}$ thick, lay in the upper level of the outcrop. Thanks to the river erosion, the aragonite travertine veins are exposed. Horizontal and vertical veins are cross-cutting each other in a complex configuration. Note that compact aragonite veins from the outcrops T2, T3, T4 and $\mathrm{T} 5$ have also been sampled and their isotopic signature had been analysed, results from $\mathrm{T} 2$ sampling is presented below.

The isotopic measurements on travertine T1 (Fig. 10A) correspond to 12 horizontal aragonite veins. Five of these veins have been dated by the U/Th method (Fig. 10B). The samples from the non dated veins are highlighted in purple and the samples from the dated veins in white (Fig. 10A). The corresponding veins are located on a schematic representation of the outcrop on Fig. 10B using the same colour code. By addition four thinner veins have also been dated in order to reflect the all outcropping growth stages and to take into account different vein orientations.

$\mathrm{U} / \mathrm{Th}$ dating shows that compact aragonite veins formed between $11.469+/-0.015$ and $4.559+/-0.023 \mathrm{ka} \mathrm{BP}$ (Fig. 10B). The U/Th dating of the two thicker veins ( 42 and 44 ) highlights that the growth of these veins occurs from the top to the bottom. This means that aragonite veins had to uplift the rock above them in order to develop. It must also be noted that some of the oldest veins occur near the top of the outcrop whereas younger veins are observed toward the base of the outcrop (Fig. 10B). U/Th datings of successive growth stages of the two thickest veins reflect growth activity lasting one to two millennia: $2.294+/-0.039$ and $0.979+/-0.024$ ka respectively for the oldest (11.469 +/-0.015 to $9.175+/-0.014 \mathrm{ka} \mathrm{BP}) 30 \mathrm{~cm}$ thick vein and the youngest $(6.830+/-0.014$ to $5.851+/-0.010 \mathrm{ka} \mathrm{BP}) 2 \mathrm{~cm}$ thick vein (Fig. 10B). After development of the oldest "thick vein", smaller veins continued to develop in the period $8.099+/-0.27 \mathrm{ka}$ to $4.559+/-0.23 \mathrm{ka} \mathrm{BP}$. The majority of the travertine record is dated between $7.387+/-0.012$ and $4.559+/-0.02 \mathrm{ka} \mathrm{BP}$. This suggests a major leakage event recorded at that time. A vertical vein with centripetal growth (Fig. 10) is dated $5.924+/-0.014 \mathrm{ka} \mathrm{BP}$ and cross-cuts the

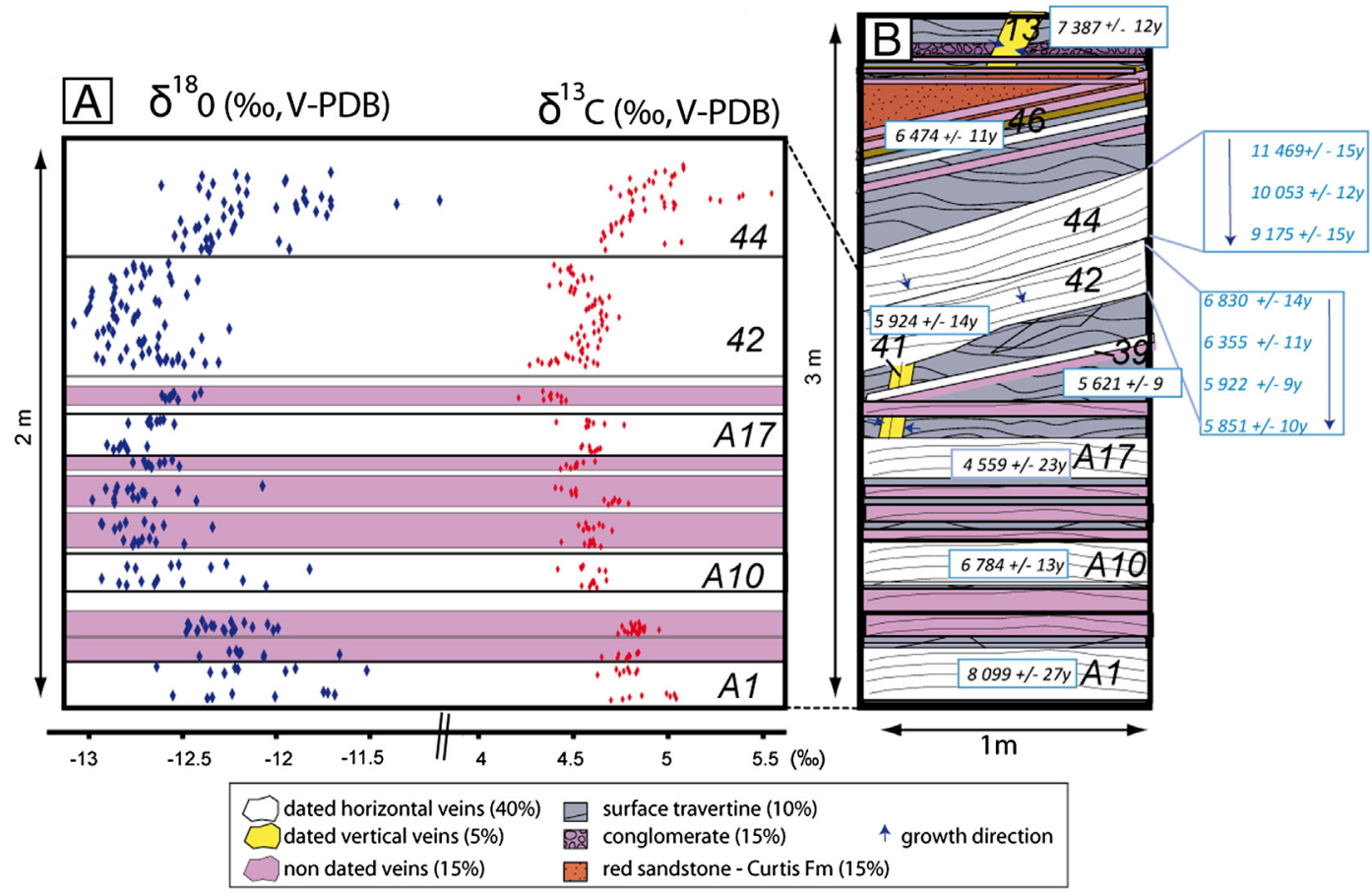

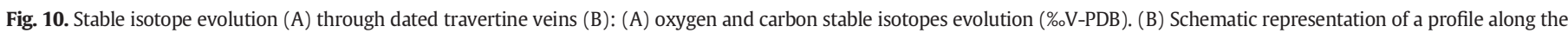
travertine with the location of the dated veins (Travertine T1, Little Grand Wash Fault, for location see Fig. 9). 
thickest vein (named 42) sealed between $6.830+/-0.014$ and $5.851+/-0.010$ ka BP.

Stable oxygen and carbon isotope signatures along the outcrop section are rather similar, although the oxygen data are more scattered (Fig. 10A). The variation range is less than $2 \%$. Between 12 and $9 \mathrm{ka}$, the $\delta^{18} \mathrm{O}$ varies between -12.7 and $-11.5 \%$ PDB and $\delta^{13} \mathrm{C}$ varies between 5 to $5.5 \%$. A slow decrease in both isotopic signatures with time can be observed. Then, from 7 ka till present, $\delta^{18} \mathrm{O}$ and $\delta^{13} \mathrm{C}$ values respectively ranges between -13.5 to $-12.6 \%$ PDB and 4.4 to $5 \%$, with signature stability from 7 ka to 4 ka.

Speleothems are normally known to grow vertically, recording the gravity field at the moment of precipitation (Gilli, 2005). However some "speleothem-like" features (Fig. 11A) may display other orientations, indicating that these precipitations have been displaced. Veins located in the hanging wall of LGW fault are curved (Fig. 11A): the speleothem-like features are not displaced in the northern compartment whereas a dip of $70^{\circ}$ to $85^{\circ} \mathrm{S}$ affects these precipitations in the southern compartment, such a distortion from the vertical dip is in
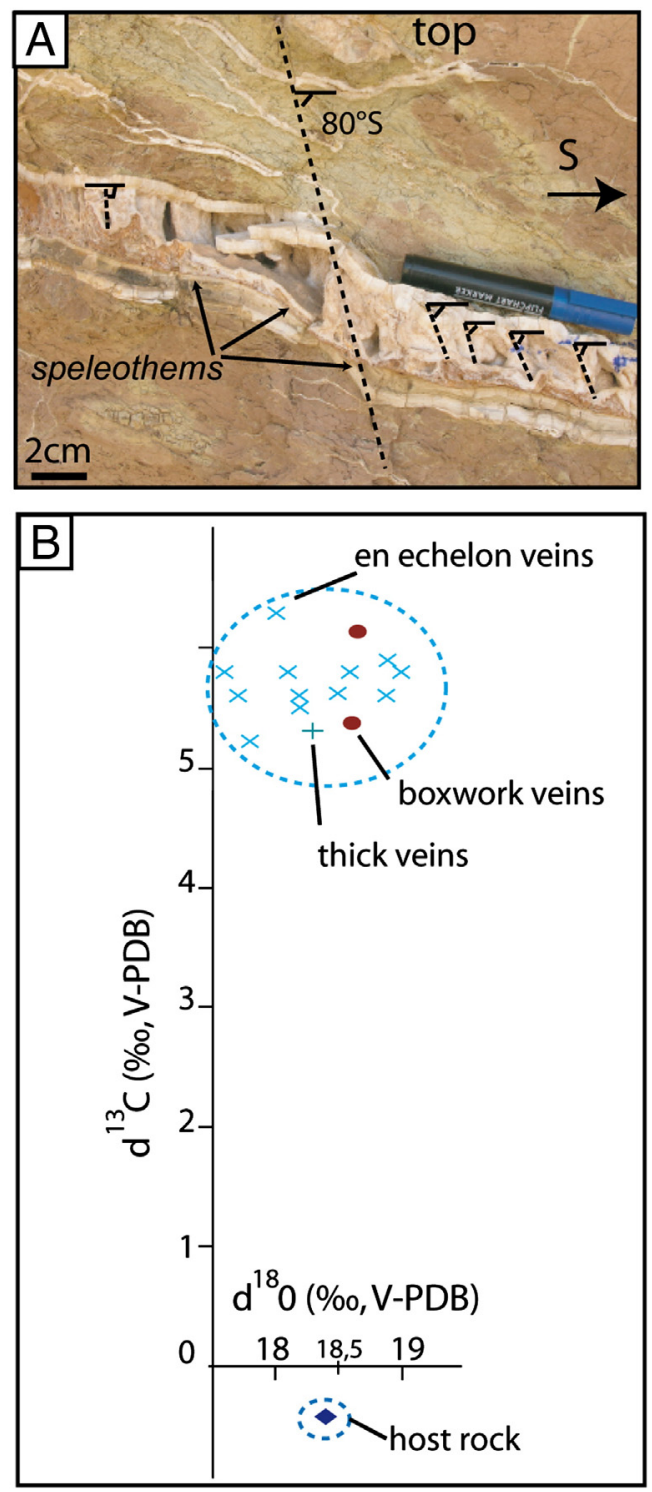

Fig. 11. Fault movement evidences: (A) Distorsion of initially vertical speleothem-like features in a sub-horizontal vein in the footwall of Little Grand Wash Fault (for location see Fig. 2B). (B) Comparison of stable isotope signature of aragonite fabrics from the boxwork veins, en echelon veins, thick travertine veins and host rock within and below the Little Grand Wash travertine 4 (for location see Fig. $2 \mathrm{~B}): \delta 13 \mathrm{C}(\%, \mathrm{~V}-\mathrm{PDB}$ ) versus $\delta 180$ (\%,V-PDB). accordance with a normal-fault displacement (Fig. 2B). In addition, a small normal fault with an $80^{\circ} \mathrm{S}$ dip and a displacement of about $3 \mathrm{~cm}$, could explain this offset observed between the southern and northern segments of the veins. The oxygen and carbon stable isotopes signature (Fig. 11B) of the en-echelon (Fig. 4C) and of the boxwork aragonite veins (Fig. 4E) are in agreement with the signature of the aragonite compact veins formed in the subsurface (Fig. 2B). This indicates that these en-echelon veins are clearly link to the normal fault movement and may have been developed from the same fluid as the aragonite veins and the boxwork veins.

\section{Discussion}

Fault opening and fault sealing mechanisms and their timings are first discussed in order to built a conceptual model of the episodic circulation along the faults. Then this conceptual model is tested by numerical modelling and the main parameters of the episodic circulation are identified and evaluated.

\subsection{Fault opening mechanisms and timing}

\section{- A brutal trigger}

Kampman et al., 2012 demonstrated a causal relationship between the quaternary $\mathrm{CO}_{2}$-pulsing and the vein opening by an isotopic analysis (C, O, Sr ratio and $\mathrm{Ba} / \mathrm{Ca}$ and SR/Ca elemental ratio). The opening of the veins is linked with a pulse of $\mathrm{CO}_{2}$ in the system following by a degassing step contemporaneous to the vein growing. The pulse of $\mathrm{CO}_{2}$ is marked by the decreasing of the $\delta^{13} \mathrm{C}$ and the degassing by a rising of the $\delta^{13} \mathrm{C}$. The covariant variation of $\delta^{13} \mathrm{C}$ and $\delta^{18} \mathrm{O}$ changes at vein scale indicates kinetically-driven vein precipitation (Kampman et al., 2014; Kele et al., 2011). In addition, veins' enrichment with heavier $\delta^{13} \mathrm{C}$ compared to the stable carbon isotopic composition of the present day Crystal Geyser water may be due to rapid $\mathrm{CO}_{2}$ degassing (Fouke, 2011; Fouke et al., 2000). Consequently, a brutal event may have triggered the fractures opening immediately followed by a fluid circulation episode.

In addition, what we see is that $30 \%$ of the volume of the boxwork structures observed in the field (Fig. 1F) is composed of clasts larger than $2 \mathrm{~mm}$ in diameter. These structures can be classified into mosaic fault breccia (Woodcock and Mort, 2008), as the clasts fit well together. Fault breccias can be generated by both hydraulic fracturing and critical fracturing which are both mechanisms associated with temporal variations in fluid pressure (Jebrak, 1997). However, the insignificant rotation of the fragments could indicate that the breccification did not occur extensively and that the dilation process in the vein was a transient phenomenon with a limited amount of open space and lead to a rapid precipitation of minerals, as attested by the lack of vein banding (Jebrak, 1992).

\section{- Driving processes}

Kampman et al. (2012), propose that the fracture openings are driven by locally elevated pore fluid pressure caused by changes in the groundwater hydrogeology by the intermittent presence of a buoyant gas cap and possibly because of transient stress changes due to postglacial crustal unloading of the regions surrounding the fault. A rising of the aragonite vein numbers from 5.6 to $7.3 \mathrm{ka}$ is indeed noticeable in the dataset of veins from 5.6 to $7.3 \mathrm{ka}$ (Fig. 10). Few twisted "speleothem-like" features and en-echelon veins are filled with carbonate mineralization contemporaneous to the Quaternary studied carbonated system (Fig. 11). However, these features are rare and cannot support the idea of Quaternary earthquakes associated with great displacement along the fault. Nevertheless, the possibility of slow motion tectonic processes could still be considered. Tectonic activity on a fault 
can indeed not only be expressed by a sudden release of stress as observed in classical earthquakes: a slow release with a long period of micro-seismicity is also observed in the seismic swarm phenomenon (Daniel et al., 2011).

\section{- Fault opening recurrence}

The bleaching phenomenon has been intensively studied in the Entrada red sandstones outcropping in TM bleached zone (Fig. 1B) and appears to be linked with an ancient $\mathrm{CO}_{2}$ circulation affecting the entire reservoir (Wigley et al., 2012, 2013a,b). In that zone, the bleaching front indeed follows lithological irregularities within the Entrada Formation (Fig. 2C). However, toward the north of the bleaching zone, numerous NS joints and fractures are affected by localized bleaching (Fig. 3). Gypsum mineralization at the centre of some of these fractures indicates the precipitation of highly salted fluids, possibly originated from the Permian Paradox formation: consequently, at some stages, these fractures created connection with deep reservoirs and enhanced circulation of fluids from different reservoirs. These NS fractures could be linked to a reactivation of the Paradox salt diaper during the Laramide orogeny (Paleocene to early Oligocene). Along LGW fault the bleaching is less extensive (Fig. 2) and is localized along shallow fractures in the sandstones and also in the shale intervals (Fig. 3), immediately connected to the carbonated system. In the upper part of the outcrops, carbonates veins indeed appears in the bleached fractures. Based on these structural observations, the bleaching could also be considered as an expression of the quaternary circulation studied at the surface. Even if the timing of the bleaching event stay hard to calibrate as no absolute dating is possible, the link between this phenomena and the fractures is clear and show that ancient $\mathrm{CO}_{2}$-enriched fluids and salted fluids have also used the same pathways.

Aragonite veins of different ages have been dated along the SW and LGW faults (Burnside, 2010; Dockrill and Shipton, 2010; Kampman et al., 2012). These investigations were supplemented in our study by 14 samples $\mathrm{U} / \mathrm{Th}$ dating from a local travertine outcrop in order to detail the recurrence and duration of the episodic circulation/sealing events along a same fault segment. The U/Th dating of the aragonite compact veins can be used to approximate these parameters. The fracture opening can indeed be determinate from the first precipitation increments and the duration of the circulation can be calculated from U/Th dating of the first and last precipitation increments. First precipitation increments had been estimated around 4.5, 5.6, 5.9, 6.4, 6.7, 6.8, 7.3, 8.0 and 11.5 for each of the compact aragonite veins studies (Fig. 10): the opening recurrences recorded vary from millenary to centennial durations ( 2294 to 979 years).

\subsection{Fault sealing mechanisms and timing}

\section{- Two main types of subsurface precipitation mechanisms}

Subsurface study of the aragonite crystallization fabric in the speleothem-like precipitations, dissolution features and sub-vertical and horizontal veins (Figs. 4 \& 5) highlighted two main mineral growth systems: (i) fan-sharp crystals in the speleothem-like precipitations and the open veins and (ii) elongated baguettes in the compact veins (Fig. 8).

Fan-shaped aragonite crystal fabrics of the open veins and speleothem-like features (Fig. 8B, C) are similar to both surface travertines (Fig. 8A) and the stalagmites fabrics extensively described in caves all around the world (Holmgren et al., 1999; Railsback et al., 1994). Stalagmites are created by water percolating along the walls of the caves and their mineralogy, i.e. ether calcite of mineralogy depend on a large number of factors, such as the surrounding rock (Denniston et al., 2000), the evaporation rate, the temperature and so on (Bar-Matthews et al., 1991; Railsback et al., 1994).
By analogy, the studied fan-shaped aragonite fabrics in open fractures and dissolution caves are witnesses of free fluid running in dissolution cavities and open spaces (Billi et al., 2007). This free fluid can either be a meteoric fluid percolating from the surface or a fluid created by previous dissolution episodes and still available below the surface. In both cases, these subsurface precipitation features do not represent a good direct record of the $\mathrm{CO}_{2}$-enriched fluid input by the fault. They even disturb the record, blurring the primary contacts between the different precipitation features (Fig. 7).

The incremental growths of aragonite sub-parallel fibres observed in the compact veins (Fig. 8D) look similar to the aragonite fabrics simulated by Bons (2001) when crystallization occurs under stress. This is confirmed by the large horizontal veins with top-to-bottom sense of growth direction that necessarily implies an uplift of the rock overlying the veins. In addition, these horizontal veins cross-cut both wall rock and former veins. Two possible sealing mechanisms can be considered:

1) The vein is opened by sub-lithostatic overpressure that uplifts the rocks but, as precipitation requires a decrease in fluid pressure, the mineral growth rate must be faster than the decreasing closing rate of the cavity due to the lowering of fluid pressure. Such a model is not very realistic and has never been reproduced experimentally.

2) Alternatively, the growth of the crystal may itself open the cavity This is what happens due to the crystallization force of the crystal in a supersaturated solution (Weyl, 1959). Natural veins growth could be driven by the crystallization force (Hilgers and Urai, 2002). This process has also been demonstrated experimentally by the development of fracture sealing driven by a supersaturated solution that is able to uplift dead weights and induce intense fracturing (Noiriel et al., 2010). This mechanism, which is described in detail in a related paper (Gratier et al., 2012), will not be discussed here. Suffice it to say that it is a plausible model for the episodicity problem that implies fluid flow from depth perpendicular to the veins during all the precipitation process.

Consequently, the distinction between the veins corresponding to precipitation in an open system and compact veins precipitated under pressure is crucial and can be unravelled with field and petrography observations.

\section{- Duration of the circulation through the fault}

As discussed above, it is crucial at this stage to consider compact aragonite veins, as it has been shown that the other veins are more likely to record events linked with free fluid percolation.

The thickest veins grew during millennia ( 1 to $2 \mathrm{ka}$ ) with some evolution of the fluid composition (Fig. 8B). The sealing duration of milimetric and centimetric veins could be roughly estimated from this calibration. The growth rate of the large vein locally varies in the range $0.08-0.71 \mathrm{~mm} / \mathrm{a}$ along the large veins profiles (Fig. 10). In order to obtain a general range of order of the growth rate over a large period of time, we propose to compute a mean growth rate for each of the large vein. In the case of Sample 42, $200 \mathrm{~mm}$ of vein thickness had been sealed in $0.979 \mathrm{ka}$ (6.830 to $5.851 \mathrm{ka}$ ); the matching mean growth rate is $0.22 \mathrm{~mm} / \mathrm{y}$. Then, in the case of Sample 44 (see Fig. 10), $215 \mathrm{~mm}$ of vein thickness had been sealed in $2.294 \mathrm{ka}$ (11.469 to $9.175 \mathrm{ka}$ ); the matching mean growth rate is $0.09 \mathrm{~mm} / \mathrm{y}$. Considering this range of growth rate variation between 0.22 and $0.09 \mathrm{~mm} / \mathrm{a}$, a $1 \mathrm{~mm}$ thick vein could be sealed in 4 to 11 years and a $1 \mathrm{~cm}$ thick vein in 40 to 111 years.

This estimation of the grow rates stay questionable. Theses veins could indeed have grown by steps, with a lake of record during several periods of time, even if no discordance in the mineralization of the thick veins (Figs. 8 \& 10) has been observed. Rate of sealing is indeed proportional to a large number of parameters, such as the flow rate and velocity, the supersaturation, the temperature gradient (Faccenna et al., 
2008; Hilgers and Urai, 2002; Lee and Morse, 1999; Lee et al., 1996; Mullin, 1993; Rimstidt and Barnes, 1980). Thus, a change in one of these parameters can totally affect the growth rate of the veins. However, with the available data, we consider that the growth rate is rather stable and we use the dating result to evaluate the possible duration of the longest episodes of fluid circulation along the fault.

According to pollen, stable isotopes, macro and micro-botanical assemblage studies in conjunction with absolute dating (Feiler et al., 1997; Salzer and Kipfmueller, 2005; Withers and Mead, 1993), the Colorado Plateau climate was colder and dryer $11 \mathrm{Ma}$ ago than nowadays, with a major mid- ground-water table level decrease 7 to $5 \mathrm{Ma}$ ago (Withers and Mead, 1993). Our dataset (Fig. 10) does not reflect this evolution of the water table and even shows an opposite trend as the largest part of the leakage evens are recorded during this period (samples A10, 39, 41, 42 and 46, Fig. 10). Several studies on tufa and travertine also show this non correlation between precipitation and dry/cold periods in endogenic systems (De Filippis et al., 2011; Rihs et al., 2000).

\subsection{Cycles of episodic precipitation/dissolution localized along the fault}

- Complex Quaternary record of a $\mathrm{CO}_{2}$-enriched fluid circulation

Focused $\mathrm{CO}_{2}$-enriched paleo fluid flow within the fault damage zone is evidenced by the Quaternary precipitations located in the fault zones, from the thin and thick aragonite veins in near-surface to the surface travertine capping the system (Fig. 2). The resulting system is a complex structure constituted of many precipitation/dissolution features (Figs. 4 \& 7). Oxygen and carbon isotopic analyses (Fig. 10 and Dockrill, 2005) highlight a common fluid signature between the thin and thick aragonite veins and the surface travertine. This signature has been studied by previous authors (Dockrill and Shipton, 2010) and is related to meteoric surface water enriched with deeper $\mathrm{CO}_{2}$-enriched water, derived from the Navajo aquifer (Kampman et al., 2009). This signature is quite uniform in all the Quaternary inactive and active travertines, and bubbling springs (Kampman et al., 2012). Consequently, the variation in precipitation products relates to different precipitation processes of a same fluid.

\section{- Record of circulation/sealing cycles}

Field observations reveal that the vertical aragonite veins are located along or parallel to the fault planes and main fractures (Figs. 5B \& 4G). Close to the surface, these vertical veins give rise to boxwork structures (Fig. 4F) or turn into a sub-horizontal position (Figs. 4B \& 5C). Based on this arrangement, a conceptual model of a circulation/precipitation cycle can be proposed (Fig. 12, cycle 1). The centripetal-growing vertical veins document a self-supporting open network that acted as fluid conduit if the fluid pressure and the amount of fluid flow were sufficiently high. Such open network includes centripetal-growing veins of various dips up to sub-horizontal fractures that cross-cut the host rock and the previous mineralization (Fig. 2E). In parallel, and close enough to the surface ( 10 to $20 \mathrm{~m}$ ) where the fluid becomes metastable with respect to $\mathrm{CO}_{2}$ degassing, thick compact horizontal veins grow from top-tobottom (Gratier et al., 2012). Finally, depressurized fluids circulating in open cavities reach free openings at the surface (geyser and/or bubbling spring) forming surface travertine. The deposition processes last

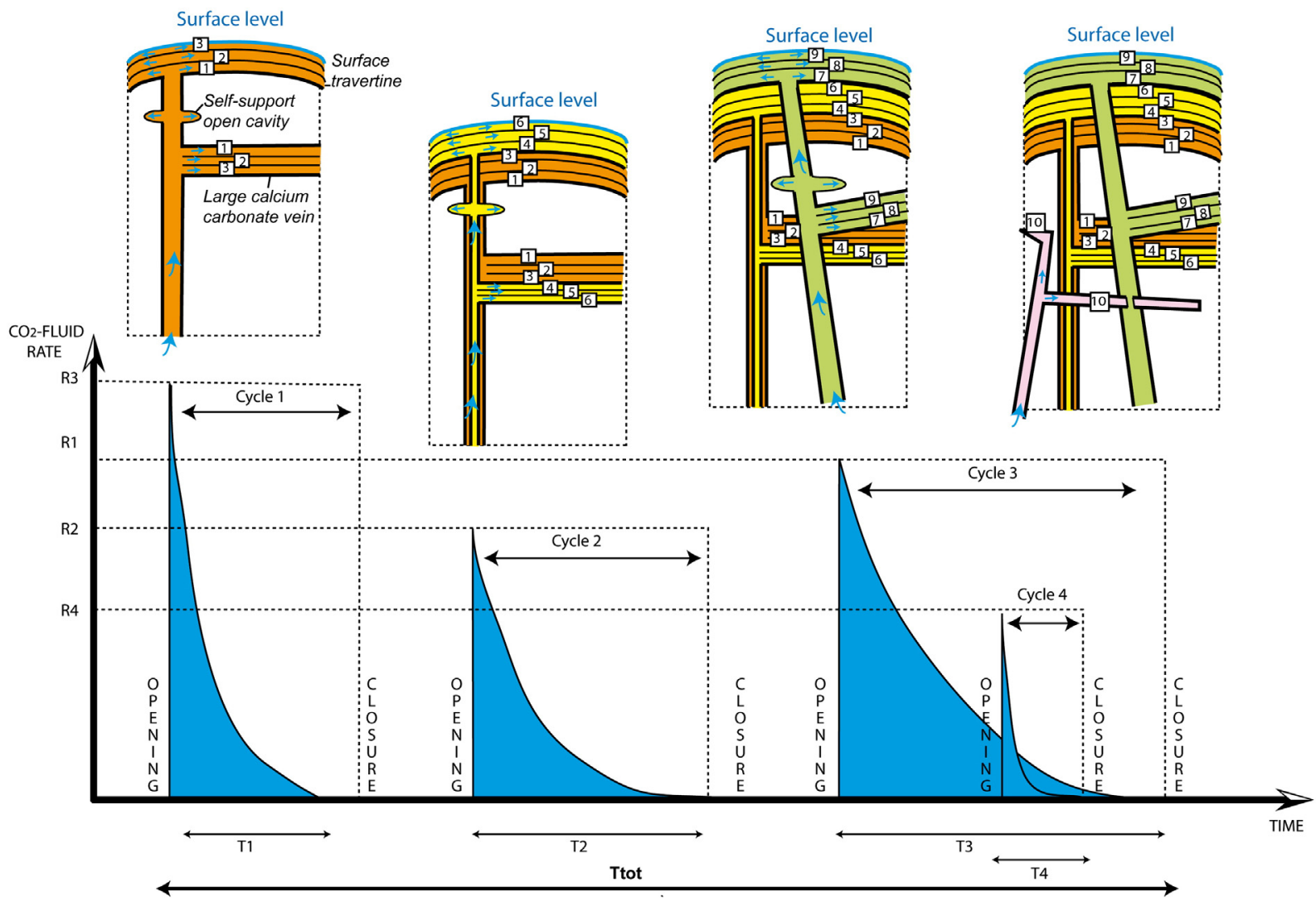

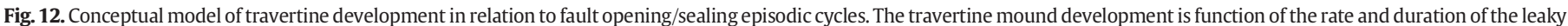

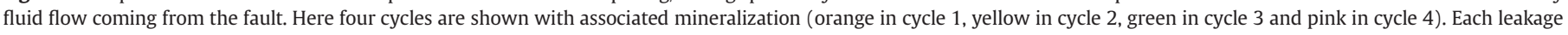

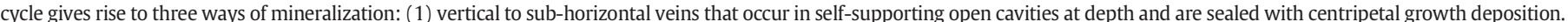

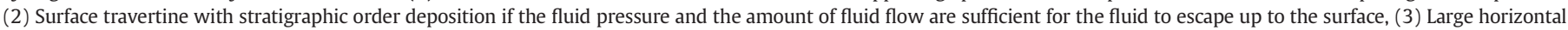

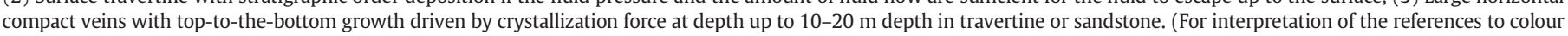
in this figure legend, the reader is referred to the web version of this article.) 
as long as large fractures are kept open at depth by the fluid pressure or the stress state and became gradually cemented until totally sealed. The compact horizontal veins are the best marker of the successive circulation episodes.

\section{- Episodicity of the fluid circulation/sealing events}

The different precipitation features can be also observed at a same structural depth, one overlapping or crosscutting the other, indicatives of a temporal evolution of the fluid circulation and sealing regime along the same fault segment. Successive dissolution/precipitation processes have indeed been documented in the field. For instance, a first precipitation of surface travertine can be cross-cut by massive veins (Fig. 2). Speleothem-like precipitations are rooted on dissolution features or open sub-vertical and horizontal veins (Fig. 7). Euhedral calcite can fill the centre of centripetal growth veins (Fig. 5A). Finally, precipitation system development depends on the rate and duration of the leaky $\mathrm{CO}_{2}$-enriched fluid flows from the depth. Even if the fault system has been plugged, fluids were able to re-use the same pathways. The fault segments are not only pipes for the fluid flow, but they can also be periodically sealed and reopened. Fig. 12 illustrates the formation of a complex system though four cycles of $\mathrm{CO}_{2}$ enriched fluid supply from the fault zone. The proposed schematic decrease of fluid flow with time is derived from the work of Renard et al. (2000) and Gratier et al. (2003) and relies on the exponential decrease of the porosity and permeability with time.

In conclusion, episodic $\mathrm{CO}_{2}$-enriched fluid circulations have been evidenced and calibrated along the faults. The resulting calcium carbonate system is complex and only a close structural and geochemical analysis of the all circulation evidence for fault system can unravel the different precipitation episodes and the mechanisms triggering the fault opening. Fault opening events are evidenced in the quaternary system with a millenary to centennial duration. The sealing phases following an opening event are particularly well archived in thick compact veins and have been calibrated, for these main events, between 1 and $2 \mathrm{ka}$. We propose to test these results in the perspective of a numerical experiment.

\subsection{Modelling the fluid flow rate evolution along fault}

- Fault sealing calibration and incrementation

As explained in the method section, a 2D finite-element code was used to solve the Darcy fluid flow equation in a permeable fault embedded in a less permeable, porous medium (Braun et al., 2003). A fault segment of length $l$ and hydraulic conductivity Kf was considered. At time $\mathrm{t}=0$ this fault is located in a matrix of dimensions $\mathrm{L} \times \mathrm{L}$ and hydraulic conductivity $\mathrm{K}_{\mathrm{m}}$ (Fig. 13).

Fault fluid transfer changes were studied using the sealing factor proposed by Gratier et al. (2003) to model changes in fluid flow along the fault. Based on pressure solution crack sealing modelling (Renard et al., 2000), the permeability around the fault was found to decrease exponentially according to:

$K_{f}(t)=K_{0} e^{-t / \tau_{s}}$

where $K_{f}$ is the fault permeability at time $t, K_{0}$ is the initial permeability of the fault, $t$ is the time, $\tau_{s}$ is the characteristic time of the sealing process (time during which the permeability decrease by a factor 2.72 ), called the "sealing factor" here. From a physical point of view, this model simulates the change in post-seismic porosity and permeability of the damaged zone around a fault, as shown by geophysical observations (Brenguier et al., 2008; Li et al., 2006). In the numerical model, the material surrounding the fault is imposed to see its permeability evolve through time, according to Eq. (1).
L
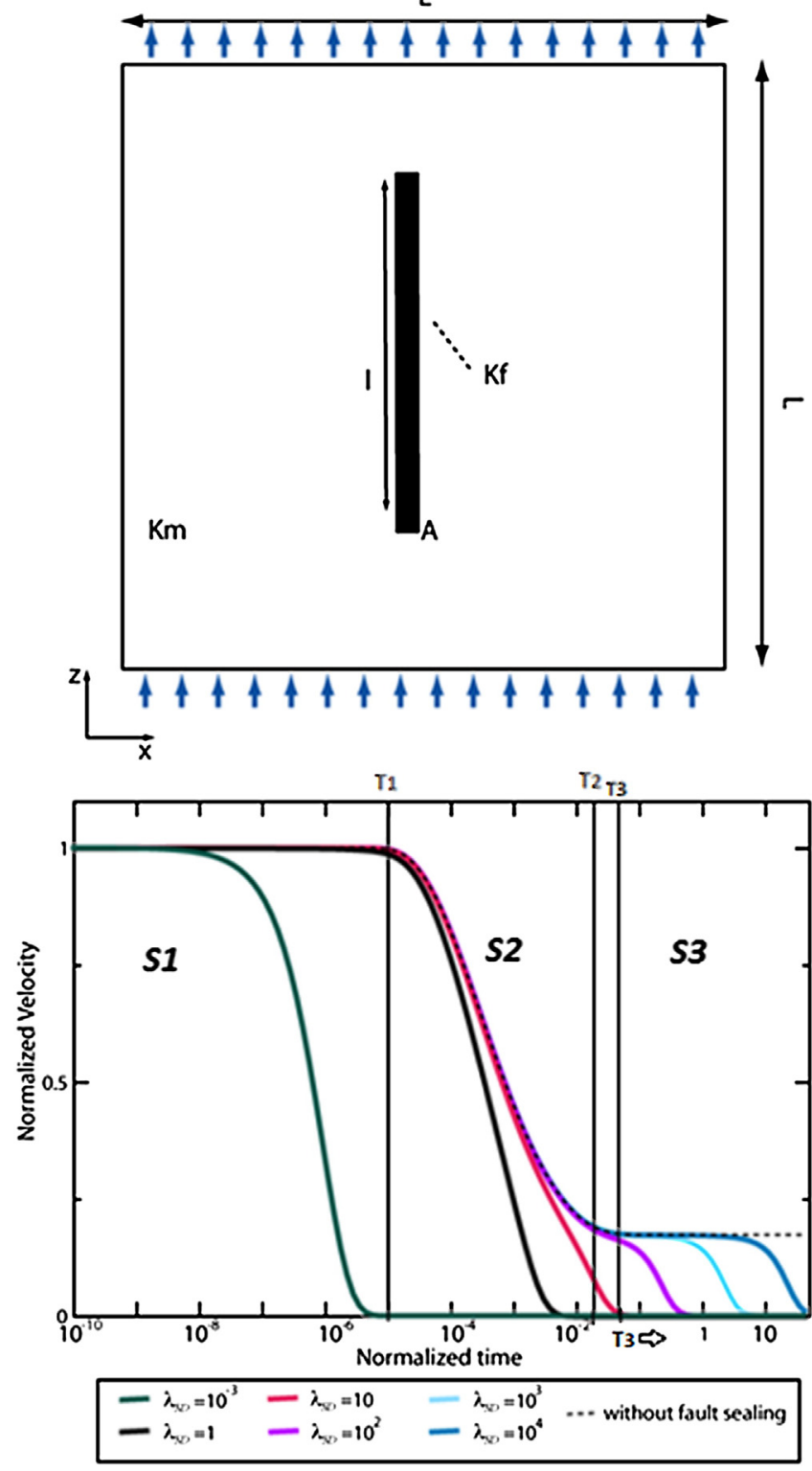

Fig. 13. Numerical test of sealing time-lapse evolution: Top: Geometry of the scenario being addressed numerically: a normal fault segment of length $\mathrm{l}$ with an hydraulic conductivity Kf is placed at time $\mathrm{t}=0+$ in a matrix of dimension $\mathrm{L} \times \mathrm{L}$ and hydraulic conductivity $\mathrm{Km}$. Fluid flow is driven by an imposed hydraulic head gradient $\Psi 0 / \mathrm{L}$. Example of a vertical fault. Bottom: Fault velocity evolution with time in six cases: without fault sealing (e.g. Darcy simple diffusion $)=$ dotted line) and with a sealing-Darcy number $\left(\lambda_{S D}\right)$ ranging from $10^{-3}$ to $10^{4}$

Without the matrix sealing factor $\tau_{s}$, fluid movement, driven by an imposed vertical pressure, takes place at a rate that is controlled by the timescale of Darcy flow $\tau_{d}$, e.g. the diffusive timescale defined by:

$\tau_{d}=\frac{S . l^{2}}{K_{m}}$

where $S$ is the specific storage and $l$ the fault length, see Braun et al. (2003).

We introduce a non-dimensional sealing-Darcy number $\left(\lambda_{\mathrm{SD}}\right)$ measuring the importance of the sealing process on the efficiency of the porous flow:

$\lambda_{\mathrm{SD}}=\frac{\tau_{d}}{\tau_{s}}=\frac{S . l^{2}}{\tau_{s} \cdot K_{m}}$.

- Evolution of the sealing time-lapses 
In order to test the impact of surrounding fault matrix sealing rate on fault fluid flow velocity with time, a series of tests along a fault segment was carried out (Fig. 13). The fault segment is vertical and located at the centre of the cell (Fig. 13, top). The variation in fault velocity with time is shown in seven cases: one without fault sealing (e.g. Darcy simple diffusion) and six with a Sealing-Darcy number $\left(\lambda_{S D}\right)$ ranging from $10^{-3}$ to $10^{4}$ (Fig. 13, bottom).

Without the addition of fault sealing with time, the variation in fluid flow through the fault, characterized by the fluid velocity in the centre of the fault, passes through three temporal stages (dotted line Fig. 13), which can be described by introducing two time scale parameters: $T_{1}=S l^{2} / K_{f}$ and $T_{2}=S l^{2} / K_{m}$ (Braun et al., 2003):

- (S1) the first stage $\left(t<T_{1}\right)$ where fluid rapidly travels through the fault, driven by the initial vertical pressure gradient at the opening of the fault;

- (S2) the second stage $\left(T_{1}<t<T_{2}\right)$ where the fluid flow in the fault leads to pressure changes in the rock at both ends of the fault, resulting in a decrease in pressure gradient between the ends of the fault and consequently a decrease in fluid velocity;

- (S3) the third stage $\left(t>T_{2}\right)$ where fluid flow in the matrix has adapted to the new pressure distribution and the fluid velocity along the fault reaches a steady-state.

This shows that the high fluid velocity that develops just after opening of the fault (at $t=0$ ) is a transitory event and that the fluid velocity in the fault decreases, even if the fault does not seal, due to the limited drainage rate in the rock.

When fault sealing is introduced, the fluid flow in the fault changes in a different manner depending on the value of the sealing-Darcy factor: three main configurations were tested: (a) predominance of Darcy diffusion $\left(\lambda_{\mathrm{SD}}>1\right)$; (b) equality of the two time scales $\left(\lambda_{\mathrm{SD}}=1\right)$; (c) predominance of sealing over Darcy diffusion $\left(\lambda_{\mathrm{SD}}<1\right)$.

- Case (a): the results are shown for $\lambda_{\mathrm{SD}}=10,10^{2}, 10^{3}$ and $10^{4}$ (pink, purple, light blue and dark blue curves, Fig. 13, bottom). Note that the stages from 0 to $T_{1}$ and from $T_{1}$ to $T_{2}$ are the same as in the case without matrix sealing. However, a new stage, defined by $t>T_{3}$, appears and shows the effect of matrix sealing: instead of reaching a finite steady-state fluid velocity value, the system completely closes and the velocity is driven to zero after a time $T_{3}$, which depends on the assumed sealing-Darcy number. $T_{3}$ is inversely proportional to the sealing-Darcy number. For a value of $10, T_{2}$ and $T_{3}$ are almost the same and the difference between $T_{2}$ and $T_{3}$ increases as the value of $\lambda_{\mathrm{SD}}$ increases.

- Case (b): $\lambda_{\mathrm{SD}}=1$ (black curve, Fig. 13, bottom). The sealing does not change the duration of stage $t<T_{1}$. However, the duration of stage $T_{1}<t<T_{2}$ is reduced by a factor 10 and fluid flow is stopped (zero velocity in the fault) before $T_{2}$ is reached. Such a system will never reach the steady-state solution predicted by the model without sealing (the "no-sealing" case).

- Case (c): $\lambda_{S D}=10^{-3}$ (green curve, Fig. 13, bottom). In this case the introduction of the fault-sealing factor leads to the complete closure of the fault before the system reaches $T_{1}$. In this situation the system is entirely controlled by the sealing process and only the first of the two stages described in the "no-sealing" case is reached.

The effect of the matrix sealing factor is thus both to shorten the duration of the period of fluid flow in the fault and, in all cases, to drive the system to a zero fluid velocity solution.

- Comparison of numerical results with natural data

Considering a sandstone matrix, fault parameters are estimated from the literature. The hydraulic conductivity $K_{\mathrm{m}}$ of sandstones ranges from $10^{-10}$ to $10^{-8} \mathrm{~ms}^{-1}$ (Brassington, 1988). The hydraulic conductivity $K_{\mathrm{f}}$ of the fault in this type of rock can be estimated to be about $10^{-6}-10^{-8} \mathrm{~ms}^{-1}$ (Istok, 1989; Phillips, 1991). Specific storage $S$ in sandstone is of the order of $0.1 \mathrm{~m}^{-1}$ (Istok, 1989; Tokunaga and Kameya, 2003). Note that changing the specific storage, fault length or matrix permeability impacts the timescale of Darcy flow (Eq. (2)).

For these values/ranges of the model parameters, we computed the value of $T_{1}$ and $T_{2}$ for three fault length values ( $100 \mathrm{~m}, 1 \mathrm{~km}$ and $\left.10 \mathrm{~km}\right)$, assuming either no sealing (orange cells in Table 1) or sealing (blue cells in Table 1). From these calculations it can be seen that the observed duration of the circulation, 1 or $2 \mathrm{ka}$, can be explained by the flow velocity decrease along the fault due to the decrease in pressure in the matrix without sealing, but only for very small faults (less than $100 \mathrm{~m}$ long). For faults larger than $100 \mathrm{~m}$, which is the dimension of most of the faults encounter in the field, a huge time is required to observe a decrease of the fluid velocity in the fault without sealing process, in fact this time reaches tens of millions years. Consequently, this demonstrates that fault sealing effect is necessary to explain the observed millennial time scale of reduction in fluid flow and sealing of a kilometric fault.

\section{Conclusion}

Fault-linked quaternary calcium carbonate mounds are complex edifices building by multiples events of fault opening and closure cycles. This study shows that:

1. The paleo-fluid flow localized along the LGW and SW faults is attested by bleaching calcium carbonate precipitation and dissolution features that attest the temporal evolution of the chemistry and the thermodynamic conditions of the exotic fluid circulation and interactions with the host rock along a same fault segment.

2. The study of the mineralization allowed distinguishing the veins precipitated in an open system from the compact veins precipitated under pressure, which gives a direct record of the $\mathrm{CO}_{2}$-enriched circulation nature and time frame. Near-vertical conduits indeed lead to two types of crystallization: (i) precipitation in self-supported open cavities at depth and in layered travertine at the surface; (ii) growth of compact veins at depth, driven by the crystallization force with top-to-bottom sense of growth direction. The carbonated vein size frequency decreases exponentially with vein width. However, in terms of volume, the largest veins represent most of the precipitated carbonates. Consequently, U/Th dating and stable isotope analysis of these compact veins provided direct information on the characteristic times and nature of such episodic circulations. For instance, noticeable sudden large events with a return period of about 1-2 ka had open fractures. These fractures formed circulation pathways that closed in about 1 to $2 \mathrm{ka}$.

3. A conceptual model of episodic circulation cycles along the faults proposes cycles of brutal fault opening mechanism, linked with overpressure fluids, followed by an exponential decrease of the $\mathrm{CO}_{2}$-enriched fluid circulation within the subsurface fractures and

\section{Table 1}

Calculation of $t_{1}$ (start of velocity decrease in ka) and $t_{2}$ (ending of fluid flow along fault in ka) for different values of fault length (from $10^{2}$ to $10^{4} \mathrm{~m}$ ). $L=$ fault length (m), $K_{f}$ fault permeability, $K_{M}$ matrix permeability, $S$ storability, $\tau_{d}$ timescale of Darcy flow $(\mathrm{s}), \tau_{s}$ timescale of sealing factor (s).

\begin{tabular}{|c|c|c|c|c|c|c|c|}
\hline$L(m)$ & $\mathrm{K}_{\mathrm{f}}$ & $\mathrm{K}_{\mathrm{M}}$ & $\mathrm{s}$ & (s) & (s) & $\mathrm{t} 1$ (ka) & t2 (ka) \\
\hline \multirow[b]{2}{*}{$10^{2}$} & \multirow[b]{2}{*}{$10^{-6}$ to $10^{-8}$} & \multirow[b]{2}{*}{$10^{-8}$ to $10^{-10}$} & \multirow[b]{2}{*}{0.1} & \multirow[b]{2}{*}{$10^{11}$ to $10^{13}$} & no & $3 \times 10^{-2}-3$ & $3-3 \times 10^{2}$ \\
\hline & & & & & $10^{8}$ to $10^{10}$ & $\begin{array}{c}3 \times 10^{-4}- \\
3 \times 10^{-3}\end{array}$ & $3 \times 10^{-3}-0.3$ \\
\hline \multirow{2}{*}{$10^{3}$} & \multirow{2}{*}{$10^{-6}$ to $10^{-8}$} & \multirow{2}{*}{$10^{-8}$ to $10^{-10}$} & \multirow{2}{*}{0.1} & \multirow{2}{*}{$10^{13}$ to $10^{15}$} & no & $3-3 \times 10^{2}$ & $\begin{array}{l}3 \times 10^{2}- \\
3 \times 10^{4}\end{array}$ \\
\hline & & & & & $10^{10}$ to $10^{12}$ & $3 \times 10^{-3}-0.3$ & $\begin{array}{l}3 \times 10^{-1} \\
3 \times 10^{1} \\
\end{array}$ \\
\hline \multirow{2}{*}{$10^{4}$} & \multirow{2}{*}{$10^{-6}$ to $10^{-8}$} & \multirow{2}{*}{$10^{-8}$ to $10^{-10}$} & \multirow{2}{*}{0.1} & \multirow{2}{*}{$10^{15}$ to $10^{17}$} & no & $\begin{array}{c}3 \times 10^{2}- \\
3 \times 10^{4}\end{array}$ & $\begin{array}{c}3 \times 10^{4}- \\
3 \times 10^{6}\end{array}$ \\
\hline & & & & & $10^{12}$ to $10^{14}$ & $\begin{array}{c}3 \times 10^{-1}- \\
3 \times 10^{1}\end{array}$ & $\begin{array}{l}3 \times 10^{1-} \\
3 \times 10^{4}\end{array}$ \\
\hline
\end{tabular}


cavities, and at the surface, forming the surface travertine features. A brutal trigger of the fault opening is attested by previous isotopic analysis (Kampman et al., 2012) of the veins and by the located hydraulic breccias with rapid veins precipitation within the fault zone. Fault normal motion is recorded in few speleothem-like features, thick veins geometry and en-echelon veins.

4. Numerical tests of the time-dependent change in fluid flow along faults show the crucial role of variable permeability around the fault. It was shown that without sealing effect the permeability distribution evolves in the matrix around the fault leading to changes in circulation and to low fluid velocity along the fault. However, durations to reach the closure of the fault are far longer than that observed in the field, except for very small faults. Consequently, it has been shown that, for the main 1000 years episodic events, a sealing process with characteristic times of about 1000 years (time during which exponentially decreasing permeability is divided by 2.72 ), must be added in the damaged zone of the fault in order to explain the observed duration of the episodic circulation.

This article focused on the mechanisms of exotic fluid circulation along the fault. In the meantime, the record provided by these veins is highly valuable regarding the Holocene climate evolution and deserve to be investigated in order to assess further the relative impact of the tectonic and the climate on the veins sealing rate and isotopic record oscillations. A slow motion tectonic event, such as seismic swarm, could also be a line to investigate, as paleo-circulations can be evidences along the LGW and SW faults at least since the Laramide Period with an opening recurrence of the quaternary veins system varying from millenary to centennial duration.

\section{Acknowledgements}

Many thanks to Luigi De Filippis and Andrea Billi for their constructive reviews. The author would also like to thank: all scientific and technical staff from IFPEN, Grenoble University, Leuven University, LSCE, CEREGE and CSIRO for their constructive comments and assistance in the field and the lab, including Julian Smith, Anne Battani, Jean-Luc Faure, Francois Roure, Herman Ravelojaona, Herman Nijs and Haley O'Brian

\section{References}

Altunel, E., Hancock, P.L., 1993. Morphology structural setting quaternary travertines pamukkale, turkey. Geol. J. 28 (3), 335-346.

Assayag, N., Brickle, M., Kampmam, N., Becker, J., 2009. Carbon constrains on $\mathrm{CO}_{2}$ degassing in cold water geyser, Green River, Utah. Energy Procedia 1 (1), 2361-2366.

Barbeau, D.L., 2003. A flexural model for the Paradox basin: implications for the tectonics of the ancestral Rocky Mountains. Basin Res. 15 (1), 97-115. http://dx.doi.org/10. 1046/j.1365-2117.2003.00194x.

Bargar, K.E., 1978. Geology and thermal history of Mammoth Hot Springs, Yellowstone National Park, Wyoming. U. S. Geol. Surv. Bull. 1444, 1-55

Bar-Matthews, M., Matthews, A., Ayalon, A., 1991. Environmental controls of speleothem mineralogy in a karstic dolomitic terrain (Soreq cave, Israel). J. Geol. 99, 189-207.

Billi, A., Valle, A., Brilli, M., Faccenna, C., Funiciello, R., 2007. Fracture-controlled fluid circulation and dissolutional weathering in sinkhole-prone carbonate rocks from central Italy. J. Struct. Geol. 29, 385-395.

Bons, P.D., 2001. Development of crystal morphology during uniaxial growth in a progressively widening vein: I. The numerical model. J. Struct. Geol. 21, 865-872.

Brassington, R., 1988. Field Hydrogeology. Geological Society of London Handbook Series. Open University Press.

Braun, J., Munroe, S.M., Cox, S.F., 2003. Transient fluid flow in and around a fault. Geofluids 3 (2), 81-87.

Brenguier, F., Campillo, M., Hadziioannou, C., Shapiro, N.M., Nadeau, R.M., Larose, E., 2008. Postseismic relaxation along the San Andreas fault at Parkfield from continuous seismological observations. Science 321, 1478-1481.

Burnside, N.M., 2010. U-Th dating of travertine on the Colorado Plateau: implications for the leakage of geologically stored $\mathrm{CO}_{2}$. (PhD thesis), University of Glasgow, England (290 pp.).

Burnside, N.M., Shipton, Z.K., Dockrill, B., Ellam, R.M., 2013. Man-made versus natural $\mathrm{CO}_{2}$ leakage: a 400 ky history of an analogue for engineered geological storage of $\mathrm{CO}_{2}$. Geology 41 (4), 471-474.
Condon, S.M., 1997. Geology of the Pennsylvanian and Permian Cutler Group and Permian Kaibab Limestone in the Paradox Basin, southeastern Utah and southwestern Colorado. U. S. Geol. Surv. Bull. 2000.

Coplen, T.B., Kendall, C., Hopple, J., 1983. Comparison of stable isotope reference samples. Nature 302, 236-238.

Cox, S.F., Etheridge, M.A., 1989. Coupled grain-scale dilatancy and mass transfer during deformation at high fluid pressures: examples from Mount Lyell, Tasmania Deformation in the presence of fluids and mineral reactions: effect of fracturing and fluidrocks interaction on seismic cycle. J. Struct. Geol. 11 (1-2), 147-162.

Crossey, L.J., Fischer, T.P., Patchett, P.J., Karlstrom, K.E., Hilton, D.R., Newell, D.L., Huntoon, J., Reynolds, A.C., De Leeuw, G.A.M., 2006. Dissected hydrologic system at the Grand Canyon: interaction between deeply derived fluids and plateau aquifer waters in modern springs and travertine. Geology 34 (1), 25-28.

Curewitz, D., Karson, J.A., 1997. Structural settings of hydrothermal outflow: fracture permeability maintained by fault propagation and interaction. J. Volcanol. Geotherm. Res. 79, 149-168.

Daniel, G., Prono, E., Renard, F., Thouvenot, F., Hainzl, S., Marsan, D., Helmstetter, A. Traversa, P., Got, J.L., Jenatton, L., Guiguet, R., 2011. Changes in effective stress during the 2003-2004 Ubaye seismic swarm, France. J. Geophys. Res. Solid Earth 116.

De Filippis, L., Billi, A., 2012. Morphotectonics of fissure ridge travertines from geothermal areas of Mammoth Hot Springs (Wyoming) and Bridgeport (California). Tectonophysics 548-549, 34-48. http://dx.doi.org/10.1016/j.tecto.2012.04.017.

De Filippis, L., Faccenna, C., Funiciello, R., Billi, A., Soligo, M., Rossetti, C., Tuccimei, P., 2011 The Lapis Tiburtinus travertine (Tivoli, Central Italy): its controversial tectonic vs paleoclimatic origin. Rend. Online Soc. Geol. Ital. 16, 15-16.

De Filippis, L., Faccenna, C., Billi, A., Anzalone, E., Brilli, M., Özkul, M., Soligo, M., Tuccimei, P., Villa, I., 2012. Growth of fissure ridge travertines from geothermal springs of Denizli basin, western Turkey. Geol. Soc. Am. Bull. 124, 1629-1645. http://dx.doi. org/10.1130/B30606.1.

De Filippis, L., Anzalone, E., Billi, A., Faccenna, C., Poncia, P.P., Sella, P., 2013a. The origin and growth of a recently-active fissure ridge travertine over a seismic fault, Tivoli, Italy. Geomorphology 195, 13-26. http://dx.doi.org/10.1016/j.geomorph.2013.04.019.

De Filippis, L., Faccenna, C., Billi, A., Anzalone, E., Brilli, M., Soligo, M., Tuccimei, P., 2013b. Plateau versus fissure ridge travertines from Quaternary geothermal springs of Italy and Turkey: interactions and feedbacks among fluid discharge, paleoclimate, and tectonics. Earth Sci. Rev. 123, 35-52. http://dx.doi.org/10.1016/j.earscirev.2013.04. 004.

De Filippis, L., Faccenna, C., Billi, A., Anzalone, E., Brilli, M., Soligo, M., Tuccimei, P., 2013c. Corrigendum to "Plateau versus fissure ridge travertines from Quaternary geothermal springs of Italy and Turkey: interactions and feedbacks among fluid discharge, paleoclimate, and tectonics". Earth Sci. Rev. 123, 35-52. http://dx.doi.org/10.1016/j. earscirev.2013.04.004.

Denniston, R., Gonzalez, L., Asmerom, Y., Sharma, R., Reagan, M., 2000. Speleothem evidence for changes in Indian summer monsoon precipitation over the last 2300 years. Quat. Res. 53, 196-202.

Deschamps, P., Hillaire-Marcel, C., Michelot, J.-L., Doucelance, R., Ghaleb, B., Buschaert, S. 2004. 234U/238U Disequilibrium along stylolitic discontinuities in deep Mesozoic limestone formations of the Eastern Paris basin: evidence for discrete uraniummobility over the last $1\{2$ million years. Hydrology and Earth System Sciences Discussions 8 (1). Copernicus Publications, pp. 35-46 (<hal-00330850).

Deschamps, P., Durant, N., Bard, E., Hamelin, B., Camoin, G., Thomas, A.L., Henderson, G.M. Okuno, J., Yokoyama, Y., 2012. Ice-sheet collapse and sea-level rise at the Bølling warming 14,600 years ago. Nature 483 (7391), 559-564.

Dockrill, B., 2005. Understanding leakage from a fault-sealed $\mathrm{CO}_{2}$ reservoir in East-Centra Utah: a natural analogue applicable to $\mathrm{CO}_{2}$ storage. ( $\mathrm{PhD}$ thesis), University of Dublin Trinity College (165 pp.).

Dockrill, B., Shipton, Z.K., 2010. Structural controls on leakage from a natural $\mathrm{CO}_{2}$ geologic storage site: central Utah, USA. J. Struct. Geol. 32 (11), 1768-1782.

Doelling, H.H., 1993. Interim geological map of the Moab $30 * 60$ minute quadrangle Grand Country, Utah. Utah Geological Survey, Open-File Report 287 (16 pp.).

Eichhubl, P., Greene, H.G., Naehr, T., Maher, N., 2000. Structural control of fluid flow: offshore fluid seepage in the Santa Barbara Basin, California. J. Geochem. Explor. 69 545-549.

Faccenna, C. Soligo, M. Billi, A., De Filippis, L, Funiciello, R., Rossetti, C. Tuccimei, P., 2008 Late Pleistocene depositional cycles of the Lapis Tiburtinus travertine (Tivoli, central Italy): possible influence of climate and fault activity. Glob. Planet. Chang. 63 299-308. http://dx.doi.org/10.1016/J.Gloplacha.2008.06.006.

Faulkner, D.R. Jackson, C.A.L, Lunn, R., Schlisch, R., Shipton, Z., Wibberley, C., Withjack, M. 2010. A review of recent developments regarding the structure, mechanics and fluid flow properties of fault zones. J. Struct. Geol. 32, 1557-1575.

Feigl, F., Leitmeier, H., 1933. "Spot" test to distinguish calcite and aragonite. Mikrochemie $13,136-138$.

Feiler, E.J., Anderson, R.S., Koehler, P.A., 1997. Late quaternary paleoenvironments of the White River plateau, Colorado, USA. Arct. Alp. Res. 29, 53-62.

Fitzenz, D.D., Miller, S.A., 2001. A forward model for earthquake generation on interacting faults including tectonics, fluids, and stress transfer. J. Geophys. Res. Solid Earth 106 (B11), 26689-26706.

Fouke, B.W., 2011. Hot-spring Systems Geobiology: abiotic and biotic influences on travertine formation at Mammoth Hot Spring, Yellowstone National Park, USA. Sedimentology $1,170-219$.

Fouke, B.W., Farmer, J.D., Des Marais, D.J., Pratt, L., Sturchio, N.C., Burns, P.C., Discipulo, M.K., 2000. Depositional facies and aqueous-solid geochemistry of travertinedepositing hot springs (Angel Terrace, Mammouth Hot Springs, Yellowstone National Park, USA). J. Sediment. Res. 70 (3), 565-585.

Frery, E., 2012. Episodic circulation of reactive fluids along faults: from travertine to basinscale based on the Colorado Plateau natural example (USA). Thesis from the 
Universities of Grenoble (France) and Leuven (Belgium) (https://tel.archivesouvertes.fr/tel-00864036/document).

Gilfillan, S.M.V., Ballentine, C.J., Holland, G., Sherwood Lollar, B., Blagburn, D., Stevens, S. Schoell, M., Cassidy, M., 2008. The noble gas geochemistry of natural $\mathrm{CO}_{2}$ gas reservoirs from the Colorado Plateau and Rocky Mountain provinces, USA. Geochim. Cosmochim. Acta 72, 1174-1198.

Gilfillan, S.M.V., Sherwood Lollar, B., Holland, G., Blagburn, B., Stevens, S., Schoell, M., Cassidy, M., Ding, Z., Zhou, Z., Lacrampe-Couloume, Ballentine, C.J., 2009. Solubility trapping in formation water as dominant $\mathrm{CO}_{2}$ sink in natural gas fields. Nature 458, 614-618.

Gilli, E., 2005. Review on the use of natural cave speleothems as palaeoseismic or neotectonics indicators. Geoscience 337 (13), 1208-1215.

Gratier, J.-P., 2011. Fault permeability and strength evolution related to fracturing and healing episodic processes (years to millennia): the role of pressure solution. Oil Gas Sci. Technol. 66 (3), 491-506.

Gratier, J.-P., Gueydan, F., 2007. Deformation in the presence of fluids and mineral reactions: effect of fracturing and fluid-rocks interaction on seismic cycle. In: Handy, M.R., Hirt, G., Hovius, N. (Eds.), Tectonic Faults, Agent of Change on a Dynamic Earth. Dahlem Workshop 2007. The MIT Press, Cambridge, pp. 319-356.

Gratier, J.-P., Favreau, P., Renard, F., 2003. Modeling fluid transfer along California faults when integrating pressure solution crack sealing and compaction processes. J. Geophys. Res. Solid Earth 108 (B2), 28-52.

Gratier, J.-P., Frery, E., Deschamps, P., Røyne, A., Renard, F., Dysthe, D., Ellouz-Zimmerman, N., Hamelin, B., 2012. How travertine veins grow from top to bottom and lift the rocks above them: the effect of crystallization force. Geology 40, 1015-1018.

Hancock, P.L., 1999. Crack-jump mechanism and its implications for stress cyclicity during extension fracturing. J. Geodyn. 27 (1), 45-60

Hancock, P.L., Chalmers, R.M.L, Altunel, E., Cakir, Z., 1999. Travitonics: using travertines in active fault studies. J. Struct. Geol. 21 (8-9), 903-916.

Heath, J.E., 2004. Hydrogeochemical characterization of leaking carbon dioxide-charged fault zones in East-Central Utah. (Master Thesis), Utah State University, Logan, Utah (166 pp.).

Hilgers, C., Urai, J.L., 2002. Microstructural observations on natural syntectonic fibrous veins: implications for the growth process. Tectonophysics 352 (3-4), 257-274.

Hintze, L.F., 1993. Geologic History of Utah. Brigham Young University.

Holmgren, K., Karlén, W., Lauritzen, S.E., Lee-Thorp, J.A., Partridge, T.C., Piketh, S., Repinski, P., Stevenson, C., Svanered, O., Tyson, P.D., 1999. A 3000-year high-resolution stalagmite-based record of palaeoclimate for northeastern South Africa. The Holocene 9, 295-309.

Istok, J., 1989. Groundwater Modeling by the Finite Element Method. Water Resources Monograph vol. 13. American Geophysical Union, Washington, DC.

Jandel, E., 2008. Monitoring géochimique par couplage entre les gaz rares et les isotope du carbone: étude d'un réservoir naturel. (PhD thesis). University of Orsay, France.

Jandel, E., Battani, A., Sarda, P., 2010. Lessons learned from natural and industrial analogues for storage of carbon dioxide. Int. J. Greenh. Gas Control 4, 890-909.

Jebrak, M., 1992. Les textures intra-filoniennes, marqueurs des conditions hydrauliques et tectoniques. Chron. Rech. Min. 506, 55-65.

Jebrak, M., 1997. Hydrothermal breccias in vein-type ore deposits; a review of mechanisms, morphology and size distribution. Ore Geol. Rev. 12, 111-134.

Kampman, N., Bickle, M., Becker, J., Assayag, N., Chapman, H., 2009. Feldspar dissolution kinetics and Gibbs free energy dependence in a $\mathrm{CO}_{2}$-enriched groundwater system, Green River, Utah. Earth Planet. Sci. Lett. 284 (3-4), 473-488.

Kampman, N., Burnside, N.M., Shipton, Z.K., Chapman, H.J., Nocholl, J.A., Ellam, R.M., Brickle, M.J., 2012. Pulses of carbon dioxide emissions from intracrustal faults following climatic warming. Nat. Geosci. 5, 352-358.

Kampman, N., Bickle, M., Maskell, A., Chapman, H.J., Evans, J.P., Purser, G., Zhou, Z., Schaller, M.F., Gattacceca, J.C., Bertier, P., Chen, F., Turchyn, A.V., Assayag, N., Rochelle, C.. Ballentine, C.J., Busch, A., 2014. Drilling and sampling a natural $\mathrm{CO}_{2}$ reservoir: implications for fluid flow and $\mathrm{CO}_{2}$-fluid-rock reactions during $\mathrm{CO}_{2}$ migration through the overburden. Chem. Geol. 369 (13), 51-82. http://dx.doi.org/10. 1016/.j.chemgeo.2013.11.015

Kato, K., Wada, H., Fujioka, K., 2003. The application of chemical staining to separate calcite and aragonite minerals for microscale isotopic analyses. Geochem. J. 37, 291-297.

Kele, S., Özkul, M., Gökgöz, A., Baykara, M.O., Alçiçek, M.C., Németh, T., 2011. Stable isotope geochemical study of Pamukkale travertines: new evidences of lowtemperature non-equilibrium calcite-water fractionation. Sediment. Geol. 238 $191-212$.

Kopf, A., Deyhle, A., Zuleger, E., 2000. Evidence deep fluid circulation gas hydrate dissociation using boron isotopes pore fluids forearc sediments from Costa Rica (ODP leg 170). Mar. Geol. 167 (1), 1-28.

Lee, Y., Morse, J., 1999. Calcite precipitation in synthetic veins: implications for the time and fluid volume necessary for vein filling. Chem. Geol. 156, 151-170.

Lee, Y., Morse, J., Wiltshko, D., 1996. An experimental verified model for calcite precipitation in veins. Chem. Geol. 130, 203-215

Li, Y.G., Chen, P., Cochran, E.S., Vidale, J.E., Burdette, T., 2006. Seismic evidence for rock damage and healing on the San Andreas fault associated with the 2004 M 6.0 Parkfield earthquake. Bull. Seismol. Soc. Am. 96, S349-S363.

Marques, J.M., Carreira, P.M., Marques, J.E., Chamine, H.I., Fonseca, P.E., Santos, F.A.M., Eggenkamp, H.G.M., Teixeira, J., 2010. The role of geosciences in the assessment of low-temperature geothermal resources (N-Portugal) a review. Geosci. J. 14 (4), 423-442.

McCaig, A.M., 1988. Deep fluid circulation in fault zones. Geology 16 (10), 867-870.

Micklethwaite, S.. Cox, S.F., 2004. Fault-segment rupture, aftershock-zone fluid flow, and mineralization. Geology 32 (9), 813-816.
Miller, S.A., 2013. The role of fluid in tectonic and earthquake processes. Adv. Geophys. 54 $1-46$.

Mullin, J.W., 1993. Crystallization. Butterworth-Heinemann, Oxford.

Noiriel, C., Renard, F., Doan, M.L., Gratier, J.P., 2010. Intense fracturing and fracture sealing induced by mineral growth in porous rocks. Chem. Geol. 269, 197-209.

Pentecost, A., 2005. Travertine. Springer-Verlag Berlin Heidelberg (305 pp.).

Person, M., 2007. Fluids, geochemical cycles and mass transport in fault zones. In: Handy, M.R., Hirth, G., Hovius, N. (Eds.), Tectonics Faults: Agents of Change on a Dynamic Earth, pp. 403-426.

Peterson, J.A., 1989. Geology and petroleum resources, Paradox basin Province. USGS Open File Rep. 88-450 U (69 pp.).

Pevear, D.R., Vrolijk, P.J., Longstaffe, F.J., 1997. Timing of Moab fault displacement and fluid movement integrated with burial history using radiogenic and stable isotopes. In: Hendry, J., Carey, P., Parnell, J., Ruffel, A., Worden, R. (Eds.), , pp. 42-45.

Phillips, O.M., 1991. Flow and Reaction in Permeable Rocks. Cambridge University Press, Cambridge, UK

Railsback, B.L., Brook, G.A., Kalini, J.C.R., Fleisher, C.J., 1994. Environmental controls on the petrology of a Late Holocene speleothem from Botswana with annual layers of aragonite and calcite. J. Sediment. Res. A 64 (1), 147-155.

Renard, F., Gratier, J.P., Jamveit, B., 2000. Kinetics of crack-sealing, intergranular pressure solution and compaction around active faults. J. Struct. Geol. 22, 1395-1407.

Renard, F., Dysthe, D., Feder, J., Meakin, P., Morris, S.J., Jamtveit, B., 2009. Pattern formation during healing of fluid-filled fractures. Geofluids 9 .

Rihs, S., Condomines, M., Poidevin, J.L., 2000. Long-term behaviour of continental hydrothermal system: U-series study of hydrothermal carbonates from the French Massif Central (Allier Valley). Geochim. Cosmochim. Acta 64, 3189-3199.

Rimstidt, J.D., Barnes, H.L., 1980. The kinetics of silica-water reactions. Geochim. Cosmochim. Acta 44, 1683-1699.

Shipton, Z.K., Evans, J.P., Dockrill, B., Heath, J., Williams, A., Kirchner, D., Kolesar, P.T. 2005. Natural leaking $\mathrm{CO}_{2}$-charged systems as analogs for failed geologic storage reservoirs. Carbon Dioxide Capture for Storage in Deep Geological Formations 2 pp. 699-712.

Salzer, M.W., Kipfmueller, K.F., 2005. Reconstructed temperature and precipitation on a millennial timescale from tree-rings in the southern Colorado Plateau, U.S.A. Clim. Chang. 70, 465-487.

Sella, P., Billi, A., Mazzini, I., De Filippis, L., Pizzino, L., Sciarra, A., Quattrocchi, F., 2014. A newly-emerged (August 2013) artificially-triggered fumarole near the Fiumicino airport, Rome, Italy. J. Volcanol. Geotherm. Res. 280, 53-66. http://dx.doi.org/10.1016/j. jvolgeores.2014.05.008.

Shipton, Z.K., Evans, J.P., Kirchner, D., Kolesar, P.T., Williams, A., Heath, J., 2004. Analysis of $\mathrm{CO}_{2}$ leakage through "low-permeability" faults from natural reservoirs in the Colorado Plateau, southern Utah. In: Baines, S.J., Worden, R.H. (Eds.), Geological Storage of Carbon Dioxide, pp. 43-58.

Solum, J.G., Davatzes, N.C., Locker, D.A., 2010. Fault-related clay authigenesis along the Moab Fault: implications for calculations of fault rock composition and mechanical and hydrologic fault zone properties. J. Struct. Geol. 32 (12), 1899-1911.

Tokunaga, T., Kameya, H., 2003. Determination of specific storage of a porous material from flow pump experiments: the theorical analysis and experimental evaluation. Int. J. Rock Mech. Min. Sci. 40 (5), 739-745.

Trudgill, B.D., 2011. Evolution of salt structures in the northern Paradox Basin: controls on evaporite deposition, salt wall growth and supra-salt stratigraphic architecture. Basin Res. 23 (2), 208-238. http://dx.doi.org/10.1111/j.1365-2117.2010.00478.x.

Utah Oil and Gas Well logs database, 2014. http://oilgas.ogm.utah.gov/Data_Center/ LiveData_Search/logs.htm.

Uysal, I.T., Feng, Y., Zhao, J.X., Altunel, E., Weatherley, D., Karabacak, V., Cengiz, O., Golding, S.D., Lawrence, M.G., Collerson, K.D., 2007. U-series dating and geochemical tracing of late Quaternary travertine in co-seismic fissures. Earth Planet. Sci. Lett. 257, 450-462.

Uysal, I.T., Feng, Y., Zhao, J.X., Isik, V., Nuriel, P., Golding, S.D., 2009. Hydrotermal $\mathrm{CO}_{2}$ degassing in seismically active zones during the Late Quaternary. Chem. Geol. 265, $442-454$.

Vignaroli, G., Aldega, L., Balsamo, F., Billi, A., De Benedetti, A.A., De Filippis, L., Giordano, G., Rossetti, F., 2014. A way to hydrothermal paroxysm, Colli Albani Volcano, Italy. Geol. Soc. Am. Bull. http://dx.doi.org/10.1130/B31139.1.

Weyl, P.K., 1959. Pressure solution and the force of crystallization - a phenomenological theory. J. Geophys. Res. 64 (11), 2001-2025.

Wigley, M., Kampman, N., Dubacq, B., Bickle, M., 2012. Fluid-mineral reactions and trace metal mobilization in an exhumed natural $\mathrm{CO}_{2}$ reservoir, Green River, Utah. Geology 40 (6), 555-558.

Wigley, M., Dubacq, B., Kampman, N., Bickle, M., 2013a. Controls of sluggish, $\mathrm{CO}_{2}$-promoted, hematite and K-feldspar dissolution kinetics in sandstones. Earth Planet. Sci. Lett. $362,76-87$

Wigley, M., Kampman, N., Chapman, H., Dubacq, B., Bickle, M., 2013b. In-situ redeposition of trace metals mobilized by $\mathrm{CO}_{2}$-charged brines. Geochem. Geophys. Geosyst. 14 (5), 1321-1332.

Withers, K., Mead, J.I., 1993. Late quaternary vegetation and climate in the Escalante River Basin on the Central Colorado Plateau. Great Basin Nat. 53 (2), 145-161.

Woodcock, N.H., Mort, K., 2008. Classification of fault breccias and related fault rocks. Geol. Mag. 145 (3), 435-440

Wycherley, H., Fleet, A. Shaw, H. 1999. Some observations on the origins of large volums of carbon dioxide accumulations in sedimentary basins. Mar. Pet. Geol. 16, 489-494. 